\title{
Assessment of Left and Right Ventricular Functions by Myocardial Performance Index in Patients with Chronic Pulmonary Disease.
}

\author{
Prof.Dr. Basil Najeebsaeed M.R.C.P., F.R.C.P. Md, Dcc ${ }^{1}$. \\ ${ }^{I}$ Ass.Prof.Dr.Mohammed.W.Al.Obaidy ** Ficms, Camb, Ficms (Resp.Medicine) \\ Dr. Azher Abbas Naser M.B. Ch.B.,Msc.(Path),Dm(Res)
}

\begin{abstract}
Background:Development of right ventricular hypertrophy and eventual right side heart failure is common in patients with chronic obstructive pulmonary disease (COPD). However, some disturbance in left ventricular (LV) function has been observed among such patients.

The co-existence between chronic obstructive pulmonary disease (COPD) and heart failure has been previously described. However, the co-existence between COPD and subclinical LV dysfunction, without the presence of heart failure symptoms, is less well understood.

The aim of the study:The aim of this study was to evaluate global function of the $L V$ and $R V$ in patients with chronic obstructive pulmonary disease (COPD) with or without pulmonary hypertension $(P H)$ by using myocardial performance index (MPI) and find out the correlation between echocardiographic findings and severity of COPD.
\end{abstract}

Patients and methods: Sixty patients with COPD without additional cardiac diseases [30 patients with COPD without PH (group 2), and 30 patients with COPD with PH (group 3)] and 30 age and sex-matched healthy subjects (group 1) were enrolled into the study. All patients underwent clinical evaluation, spirometry, electrocardiography and standard and tissue Doppler echocardiography. Various echocardiographic parameters of $L V$ and $R V$ functions were compared with indices of pulmonary function test and pulmonary arterial pressure. RV myocardial performance index (RVMPI) and LVMPI were obtained by pulsed wave Doppler tissue.

Results:RVMPI was higher in both group $2(0.57 \pm 0.11)$ and group $3(0.96 \pm 0.05)$ than group $1(0.42 \pm 0.043)$ $(P<.001)$, and was higher for group 3 than in group $2(P<.001)$. LVMPI was higher for group $3(0.7 \pm 0.083)$ than in both group $1(0.5 \pm 0.034)$ and group $2(0.56 \pm 0.037)(P<.001)$.

For patients with COPD, LVMPI was positively correlated with age, heart rate, pulmonary arterial systolic pressure and RVMPI and negatively correlated with tricuspid annular plane systolic excursion and forced expiratory volume in 1 second. In multiple linear regression analysis $(R=0.674)$, LVMPI was independently associated with forced expiratory volume in 1 second (FEVI) (Beta $=1.133, P=0.007)$, pulmonary arterial systolic pressure (Beta $=-0.758, P=0.128)$, and RVMPI (Beta $=1.436, p=0.009)$.

$L V$ diastolic function parameters ( $A, E / A$, and deceleration time of $E$ ) were impaired for groups 2 and 3 compared with group 1.Mitral early diastolic and late diastolic annular velocities ratio (Em/Am), were significantly lowest in COPD patients with $\mathrm{PH}(0.77 \pm 0.066)$, and the isovolumetric relaxation time (IVRT) was significantly longer in group $3(105.43 \pm 4.21 \mathrm{~ms})$ and group $2(102.27 \pm 4.45 \mathrm{~ms})$ in relation to control group $(71.2 \pm 5.51 \mathrm{~ms})$.

$R V$ diastolic function, E/A ratio was higher in the control subjects compared with the patient groups. The tricuspid inflow velocities ratio (E/A) was significantly lowest value in COPD $p=$ atients with $P H(0.84 \pm 0.04)$ and the isovolumetric relaxation time (IVRT) was significantly longer in group 3(98.87 $\pm 8.41 \mathrm{~ms})$ and group $2(77.5 \pm 4.57 \mathrm{~ms})$ in relation to control group $(75.37 \pm 5.2)$.

$L V$ end-diastolic diameter was significantly lower for group $3(40 \pm 2.665)$ than group 1(46.2 \pm 2.295$)$ and group $2(44.2 \pm 3.367)$. LV mitral valve annular velocity $\left(S^{\prime}\right)$ was lowest in goup3 $(9.64 \pm 0.92)$.However, conventional systolic function parameters and IVSd were not different among the groups. Systolic and diastolic $R V$ diameters were higher and $R V$ fractional shortening was lower for group 3 than the other two groups. TAPSE was significantly lower for group 3(16.07 \pm 3.54$)$ compared with group $1(21.7 \pm 2.71)$ and group 2 (20.83 \pm 2.69$)$, but differences between groups 1 and 2 was not statistically significant.

Conclusion:Both LV systolic and diastolic functions are impaired in COPD, especially in patients with PH. This impairment is independently associated with pulmonary arterial systolic pressure, RVMPI, and FEVI. Left and right ventricular diastolic function and $L V$ and $R V$ global function are affected in COPD patients especially with progression of the disease. COPD patients with pulmonary hypertension are more liable to LV and RV diastolic and global dysfunction than normal pulmonary pressure COPD patients. Doppler tissue echocardiography is a better tool in the assessment of $L V, R V$ function. 


\section{Introduction}

Chronic obstructive pulmonary disease (COPD) is a major cause of chronic morbidity and mortality throughout the world. Many people suffer from this disease for years and die prematurely from it or its complications. COPD is the fourth leading cause of death in the world, ${ }^{(1)}$ and further increases in its prevalence and mortality can be predicted in the coming decades. ${ }^{(2)}$

Pulmonary hypertension ( $\mathrm{PH})$ is an important complication in the natural history of chronic obstructive pulmonary disease (COPD). Its presence is associated with reduced survival and greater use of healthcare resources. ${ }^{(3)}$

The cardiovascular sequelae of chronic obstructive pulmonary disease (COPD) have been recognized for decades. ${ }^{(18)}$ The spectrum of cardiovascular disease includes right ventricular (RV) dysfunction, pulmonary hypertension (PH), coronary artery disease (CAD), and arrhythmias ${ }^{(19)}$ Pulmonary vascular disease associated with COPD increases morbidity and worsens survival. ${ }^{(18,20)}$ Patients with COPD also carry an increased risk of mortality due to arrhythmia, myocardial infarction, or congestive heart failure compared with those who do not. $(19,20,21)$ The Lung Health Study showed that a substantial proportion of deaths in patients with mild COPD was the result of cardiovascular complications, and a recent large epidemiologic study revealed increased cardiovascular mortality, particularly in patients younger than 65 years with COPD. ${ }^{(22,}{ }^{23)}$ Because cardiac abnormalities clearly contribute to the overall morbidity associated with COPD, an understanding of their role and potential for treatment is vital.

Although the true prevalence of PH in COPD is unknown, an elevation of pulmonary arterial pressure is reported to occur in $20 \%-90 \%$ of patients when measured by right heart catheterization with some evidence that pulmonary hemodynamic worsens with worsening airflow obstruction. ${ }^{(25)}$ Two studies have shown an abnormal increase in mean pulmonary arterial pressure (Ppa) in COPD of $0.4-0.6 \mathrm{mmHg}$ per year. These studies illustrate that PH in COPD progresses slowly and occurs in mild as well as severe forms of disease. ${ }^{(26)}$

Although RV dysfunction and $\mathrm{PH}$ are common in COPD, increases in mean pulmonary artery pressures tend to be mild to moderate. Previous estimates of the prevalence of PH in COPD had been 20 to 30\%, with some evidence that pulmonary hemodynamics worsen with worsening airflow obstruction. ${ }^{(27)}$ Overall, current data suggest that PH occurs commonly in COPD but that it is rarely severe.Echocardiography is an attractive method for measuring right-sided pressures in patients and has been used as a screening tool for PH; however, the accuracy of echocardiography for assessing of pulmonary hemodynamics in COPD has recently been called into question. ${ }^{(54)}$ In 374 patients being evaluated for lung transplant, an estimate of pulmonary artery systolic pressure was possible in only $38 \%$ of the patients with COPD. Furthermore, accuracy was only 56\% compared with right heart catheterization. ${ }^{(55)}$ Compared with invasive measures, echocardiography had a sensitivity of $60 \%$ and a specificity of $74 \%$. Although right heart catheterization is believed to provide the most accurate assessment of right-sided pressures, interpretation of pressure waveforms in patients with severe emphysema can be complicated by significant swings in pleural pressures due to hyperinflation and gas trapping in overly compliant lungs. Its invasive nature also precludes its routine use in the evaluation of COPD. Its use is reasonable, however, in patients in whom significant elevations are suspected or in patients being evaluated for potential LVRS or transplant.BNP is now widely accepted as a diagnostic tool in the management of left ventricular dysfunction. ${ }^{(56,57)}$ The role of BNP in the assessment of RV dysfunction, particularly in the setting of chronic lung disease, is less clear. A recent study of patients with chronic lung disease showed BNP to be elevated in patients with significant $\mathrm{PH}$ and was a predictor of death. ${ }^{(30)}$

\section{II.The Aim Of The Study}

The first aim of this study was to investigate the global function of the LV in patients with COPD by the MPI and, secondarily, to investigate associations between the LV MPI (LVMPI) and other clinical and echocardiographic variables and find out the correlation between echocardiographic findings and pulmonary function test. 


\section{3-Patients and methods \\ Patients}

This prospective study was conducted over 12 month period from $1^{\text {st }}$ of June 2014 to $30^{\text {th }}$ of May 2015. The study participants consisted of 30 age-matched healthy control subjects $(61.47 \pm 7.47$ years) (group 1), 30 patients with COPD without PH (62.87 \pm 7.26 years) (group 2), and 30 patients with COPD with PH (61.47 \pm 7.47 years) (group 3). COPD patients recruited from inpatient and outpatient departments of pulmonology and medicine of Baghdad teaching hospital were evaluated. Patients aged $\geq 50$ years with $\geq 10$ pack-year smoking histories and clinically stable were included.Inclusion Criteria: (1) All diagnosed male and female COPD patients.

(2) Clinically stable patients. Exclusion criteria were as follows: (1) a primary diagnosis of other pulmonary diseases as: asthma, pulmonary tuberculosis, bronchiectasis, interstitial pulmonary disease, sleepapnea/hypopnea syndrome or lung cancer. (2) unstable cardiorespiratory status, defined as the occurrence of respiratory failure, bronchopulmonary infection, or congestive heart failure in the previous 2 months; (3) structural diseases of the heart (valvular heart disease, congenital heart disease, and cardiomyopathy) (4) ischemic heart disease defined as a primary diagnosis of unstable angina, typical angina pectoris, prior myocardial infarction, positive exercise test result or positive coronary angiography findings.(5) In addition, congestive heart failure (New York Heart Association class III or IV), systemic arterial hypertension or other chronic diseases, such as uncontrolled diabetes mellitus, atrial fibrillation, complete right or left bundle branch block; kidney or liver failure and cancer were excluded.(6) Patients were also excluded if they required psychotropic medication, a change in medication dose for more than 4 weeks, or a change in any medication that may affect hemodynamic function, such as theophylline, steroids, diuretics, digitalis, or antihypertensive agents, as these could affect assessment of the progression of COPD (7) Patients for whom good quality echocardiographic images could not be obtained, have been excluded.

These selection criteria were set because this study aimed to evaluate the usefulness of additional assessment of RV and LV function, compared with the usual assessments undertaken in patients with COPD.

Thirty healthy subjects (men, women) from the same area were recruited as control subjects. All control subjects identified themselves as healthy volunteers and were companions of non-COPD patients.

The control group had no cardiovascular or any other systems disease, and had normal physical examination, chest roentgenogram, electrocardiogram, and 2-dimensional and Doppler echocardiogram, with normal spirometry results.

None of the control subjects were using any kind of treatment or prophylaxis for chronic disease, such as hypertension, diabetes mellitus, coronary artery disease, or other diseases that could affect the results of our study. After a routine interview to exclude individuals with all types of acute or chronic disease, the volunteers underwent clinical examination and some basic laboratory investigations to exclude those with diseases that can affect the cardiac state.

\section{Methods:}

The data were collected in special designed questionnaire filled by the researcher through a standardized approach of history which include the personal data (age, sex, occupation, residence, and marital status), social data (smoking status) and symptoms of patients., examination (Clinical examination of patients included examination of vital signs, examination for cyanosis, leg edema, JVP, examination of chest for anteroposterior dimension and expansion of chest, breath sounds and added sounds, examination of precordium for left parasternal impulse, intensity of pulmonary component of $\mathrm{S} 2$, murmur of tricuspid regurgitation and examination of abdomen for hepatomegaly and ascites) and investigation for both cases and control.

After having a written informed consent from all participants, every one of them were subjected to routine investigations, including complete blood count, lipid profile, blood sugar, blood urea, serum creatinine and the following procedures: resting ECG tracing, standard x-ray, systolic and diastolic blood pressure measurement, echocardiography and resting spirometry.

\section{Electrocardiogram (ECG)}

ECGs were performed on all of the patients. A Schiller device (Schiller AG, Cardiovit CH-6341,Baar, Swiss made) was used with 12 simultaneous leads (DI, DII, DIII, V1, V2, V3, V4, V5, V6, aVR, aVL and aVF) .The diagnosis of ECG alteration was based on the criteria used in the literature ${ }^{(76)}$ The same examiner performed all tests.

\section{Spirometry}

Spirometry was performed using the MASTERLAB spirometer (MASTELAB pro, B/IEC 601-1, Erich Jaeger, made in Germany) before and 15 minutes after the inhalation of 400 mcg of salbutamol according to the criteria set by the American Thoracic Society. ${ }^{(77)}$ The forced expiratory volume in one second(FEV1), expressed 
as percentage of expected normal value and as the percent of vital capacity (VC;FEV1/FVC) was analyzed. Patients were diagnosed to have COPD if they had FEV1/FVC ratio less than 0.70 .

The COPD diagnosis was confirmed according to the guidelines established in the Global Initiative for Chronic Obstructive Lung Disease (GOLD) ${ }^{(78)}$ : a post-bronchodilator FEV/forced vital capacity (FVC) ratio $<0.70$ and an increase $<15 \%$ or $200 \mathrm{~mL}$ inFEV1after inhalation of a $\beta 2$ agonist.

\section{Severity of COPD was evaluated according to GOLD $2010,{ }^{(79)}$ and patients were classified into four groups as follows:}

Stage I (Mild): post bronchodilator FEV1 $\geq 80 \%$ predicted

- Stage II (Moderate): $50 \% \leq$ post bronchodilator FEV1 $<80 \%$ predicted

_ Stage III (Severe): $30 \% \leq$ post bronchodilator FEV1 $<50 \%$ predicted

- Stage IV (Very severe): post bronchodilator FEV1 $<30 \%$ predicted or $<50 \%$ predicted plus chronic respiratory failure.

Echocardiography

In all individualsechocardiographic examinations were performed by using a machine (Philips Ultrasound CX50 Diagnostic Ultrasound system, Bothell, WA 98021 USA) with a 1.5-4 MHz sector transducer probe. Routine echocardiography with standard projections was done initially and followed by Doppler flow tracing registration at the level of mitral and tricuspid valves. Further, tissue Doppler echocardiography (TDE) obtained images were registered.

Measurements and recordings were made during normal breathing at end-expiration and were performed by the same staff using the same equipment throughout the study period. M-mode and Doppler recordings were obtained at a monitor speed of $100 \mathrm{~mm} / \mathrm{s}$.

All measurements were calculated from an average of 3 consecutive cardiac cycles. Echocardiography was reviewed to assess the pericardium, valvular anatomy and function, left and right side chamber size and cardiac function.Echocardiography was performed in all patients according to the same protocol and included the following:

\section{Functions}

The assessment of left ventricular systolic function consisted of fractioningshortening(FS\%), left ventricular ejection fraction (EF \%), and the mitral valve peak annular velocity measured at the left ventricular lateral wall (Sm). LV end-systolic and end-diastolic diameters, end-diastolic interventricular septal thickness, and end-diastolic LV posterior wall thickness were measured. As standard indexes of global LV systolic performance, LV EF\% and LV FS\% were obtained. LV fractional shortening was taken as: (LV end-diastolic diameter - LV end-systolic diameter)/LV end-diastolic diameter (25\%-43\% for male, 27-45\%for female). LV EF was determined by using the formula of Teichholz et al. ${ }^{\left({ }^{80}\right)} \mathrm{EF}$ (ejection fraction) $=$ measure of how much enddiastolic value is ejected from LV with each contraction (52\%-72\%for male, $54-74 \%$ for female). Measurement of LV EF\% by M-mode by measurement of LV systolic and diastolic dimensions obtained through long-axis parasternal approach in M-mode projection.

M-mode echocardiographic measurements were obtained on the basis of the standards of the American Society of Echocardiography. ${ }^{\left({ }^{80}\right)} \mathrm{LV}$ diastolic filling patterns were determined by the mitral inflow pulsed wave Doppler examination. Pulsed Doppler recordings of the mitral inflow velocities were obtained from the apical 4chamber view by placing the sample volume between the tips of the mitral leaflets. ${ }^{\left({ }^{(2)}\right.}$ The diastolic parameters were measured from at least three beats and were defined as follows: E-wave, early maximal transmitral flow velocity; A-wave, peak velocity during atrial contraction in late diastole; and ratio between the early peak transmitral flow velocity (E) and late peak atrial systolic velocity (A) [E/A ratio]. Also the left ventricular diastolic function was assessed by measuring the isovolumic relaxation time (IVRT).

To measure myocardial performance index, the Pulsed wave tissue Doppler echocardiography was performed with a 2-mm sample volume placed at the lateral, septal, anterior, and inferior side of the mitral annulus from the apical 2- and 4-chamber views. Doppler time intervals were measured from recordings. The means of the measurements of these sites were calculated. The interval between the end of the late diastolic annular velocity and the onset of the early diastolic annular velocity $(a)$ is equal to the sum of isovolumic contraction time (IVCTm) and ejection time (ETm) and isovolumic relaxation time (IVRTm). ETm (b) was measured as the duration of the systolic annular velocity. The sum of IVCTm and IVRTm was obtained by subtracting $b$ from $a$. Then, the LVMPI was calculated as: $\left(a_{-} b\right) / \mathrm{b}$ (Figure 1). ${ }^{(83,84)}$

The IVRTm was measured from the pulsed wave Doppler tissue recordings as the time interval from the end of the systolic annular velocity to the onset of the early diastolic annular velocity. The IVCTm was obtained by subtracting IVRTm from $\left(a_{-} b\right)$.Left ventricular diastolic dysfunction is said to be present when 
E/A is $<1.3$ (age group 45-49 years), <1.2 (age group 50-59 years), <1.0 (age group 60-69 years), and <0.8 (age group $=70$ years). ${ }^{(85)}$

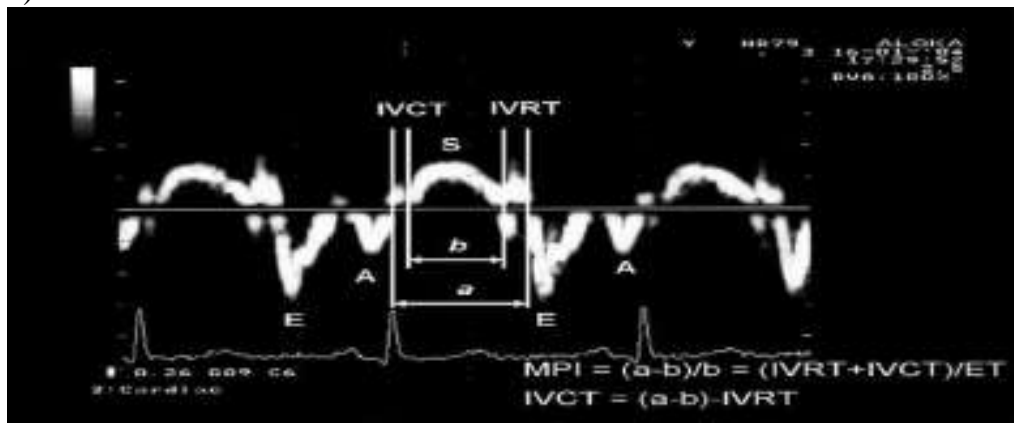

Figure1: Doppler-derived myocardial performance index $(M P I),\left(a_{-} b\right) / b$, is calculated by measuring two intervals in same cardiac cycle from Doppler tissue recordings: (1) $a$ is interval between cessation of late diastolic annular velocity $(A)$ and onset of early diastolic annular velocity $(E)$; and $(2) b$ is duration of systolic annular velocity $(S)$. Isovolumic relaxation time (IVRT) was measured as time interval between end of $\mathrm{S}$ and onset of E. Isovolumic contraction time $(I V C T)$ was obtained by subtracting IVRT from $\left(a_{-} b\right)$. ET, Ejection time.

\section{RV Functions}

RV end-systolic and end-diastolic diameters were measured from the subcostal views. Parameters obtained through subcostal approach in M-mode projection where analyzed: end-diastolic right ventricular diameter (RVD), right ventricular free wall thickness (RVWT) and interventricular septum thickness (IVS).

As indexes of global RV systolic performance, RV percent fractional shortening and tricuspid annular plane systolic excursion (TAPSE) were obtained. RV fractional shortening was taken as: (RV end-diastolic diameter _ $\mathrm{RV}$ end-systolic diameter)/RV end-diastolic diameter. TAPSE was measured in the apical 4-chamber view. Care was taken to avoid echo dropouts of endocardial edges in regions of the tricuspid annulus and RV apex. The distance between the tricuspid annulus and the RV apex was measured at end diastole and end systole of the same cardiac cycle, and TAPSE was calculated (in millimeters) as the difference between end-diastolic and endsystolic measurements. ${ }^{(86)}$

To measure the tricupid flow velocity, the Doppler sample volume was placed in the RV near the tricuspid orifice in the apical 4-chamber view. ${ }^{(87)}$ The measurements were taken at end-expiration. From Doppler recordings of transtricuspid flow, the following variables were measured: E, A, and E/A ratio.

The right heart circulation was assessed as follows. Colour Doppler flow imaging was used to detect and semiquantify pulmonary and tricuspid valve regurgitation. Tricuspid regurgitantflow was recorded from the apical 4chamber by color flow Doppler technique and the maximum jet velocity was measured by continuous wave Doppler without the use of intravenous contrast.

The RV out-flow tract velocity was recorded from the parasternal short-axis view with the pulsed-wave Doppler sample volume positioned just below the pulmonary valve. RV out-flow acceleration time and tricuspid regurgitation velocity were measured to determine if there was any evidence of PH. Results were considered to be suggestive of $\mathrm{PH}$ when the tricuspid regurgitation velocity was $>2.8 \mathrm{~m} / \mathrm{s}$ without pulmonary valve stenosis, ${ }^{(88,89)}$ when PA acceleration time was $<90 \mathrm{~ms}$, or when PA acceleration time/PA ejection time was $<0.3$. ${ }^{(90,91,92)}$

The systolic pressure gradient between the RV and right atrium was measured by calculating the maximum peak velocity by means of the Bernoulli equation. As pulmonary stenosis was excluded in all patients, it was agreed that the RVSP value obtained, relates to the pulmonary artery pressure. The modified Bernoulli's equation was used to calculate pulmonary artery pressure (PAP). Systolic PAP $(\mathrm{mmHg})=4 \mathrm{x}$ tricuspid systolic jet+ right atrial mean pressure. Right atrial pressure is estimated to be $5 \mathrm{mmHg}$ when the diameter of inferior vena cava is $<1.7 \mathrm{~cm}$ and a $50 \%$ decrease in the diameter with inspiration, $10 \mathrm{mmHg}$ when IVC is $>1.7 \mathrm{~cm}$ with a normal inspiratory collapse $>50 \%$, and $15 \mathrm{mmHg}$ when IVC is $>1.7 \mathrm{~cm}$ and inspiratory collapse is $<50 \%)$. ${ }^{(93)}$

Myocardial performance index (MPI) was calculated by the sum of isovolumic contraction time and relaxation time divided by ejection time. Mean MPI value was calculated. ${ }^{(93)}$

Pulsed wave Doppler tissue echocardiographic recordings were obtained by placing the sample volume at the lateral corner of the tricuspid annulus from the apical 4-chamber views. The interval between the end of the late diastolic annular velocity and the onset of the early diastolic annular velocity $(a)$ is equal to the sum of isovolumic contraction time (IVCTt) and ejection time (ETt) and isovolumic relaxation time (IVRTt). ETt (b) was measured as the duration of the systolic annular velocity. The sum of IVCTt and IVRTt was obtained by subtracting $b$ from $a$. Then, the RV MPI (RVMPI) was calculated as $\left(a \_b\right) / b .^{(83,84)}$ 
The IVRTt was measured from the pulsed wave Doppler tissue recordings as the time interval from the end of the systolic annular velocity to the onset of the early diastolic annular velocity. The IVCTt was obtained by subtracting IVRTt from $\left(a_{-} b\right)$.

When systolic PAP is more than $35 \mathrm{mmHg}$ then pulmonary hypertension $(\mathrm{PH})$ is established according to 4th world symposium on pulmonary hypertension, Right ventricular free wall thickness and cavity dilatation were measured using 2D echo. Patients were categorized into mild, moderate and severe PAH having 35$39 \mathrm{mmHg}, 40-59 \mathrm{mmHg}$ and more than $59 \mathrm{mmHg}$ pressure respectively. ${ }^{(95)}$

\section{IV.StatisticalAnalysis}

The data follow normal distribution and the test of normality was done using Anderson - Darling test. Dichotomous data are described as numbers and percentages. Continuous variables are described as means \pm standard deviation.. All comparisons between groups were performed using the ANOVA one way and post hoc Tukey test.

A linear regression analysis and regression correlation coefficient was employed to investigate the relation between obtained data. Multiple linear regression analysis was done to evaluate whether the variables (age, HR, TAPSE, $\mathrm{FEV}_{1}$, RVMPI, and PASP) were dependent or independent predictor for LVMPI and standardized correlation coefficient (beta) and partial correlation coefficient were used to assess this fact.

Level of significant (alpha) was considered at 0.05 so any $\mathrm{p}$ values below this considered statistically significant.

All analyses were performed using Minitab 17 and SPSS version 20 statistical software (SPSS, Inc., Chicago, Illinois).

\section{V.Results}

The study sample composed of 30 age - matched control subjects $(61.47 \pm 7.47$ years) (group 1) and 60 cases of COPD patients ( $83 \%$ are male and 17\% female), 30 of them are without pulmonary hypertension (62.87 \pm 7.26 years) (group 2) and 30 with pulmonary hypertension (61.47 \pm 7.47 years) (group3).

In the studied COPD patients, 19(63.3\%) COPD patients with $\mathrm{PH}$ and 15(50\%) patients without PH had severe COPD while 11(36.7\%) COPD patients with PH and 15(50\%) patients without PH had moderate COPD, table (1).

Table (1): Patients' classification according to severity of COPD and incidence of pulmonary hypertension in

$$
\text { COPD patients }
$$

\begin{tabular}{|l|l|l|l|l|}
\hline \multirow{3}{*}{ Variable } & \multicolumn{2}{|l|}{ FEV1\% } & \multicolumn{2}{l|}{} \\
\cline { 2 - 5 } & moderate & Severe & No & $\%$ \\
\cline { 2 - 5 } & No & 50 & 15 & 50 \\
\hline Patients without PH & 15 & 36.7 & 19 & 63.3 \\
\hline Patients with PH & 11 & 43.3 & 34 & 56.7 \\
\hline Total & 26 & 5.3 & \\
\hline
\end{tabular}

The clinical characteristics, spirometry parameters and PASP results of study population are shown in Table (2). Statistically important differences with respect to age, gender values in COPD patients and in the control group, were not found. In the present study, there was a highly statistically significant difference in heart rate between group 1 and 2, group 1 and 3, and group 2 and 3; we found that patients with pulmonary hypertension had significantly highest heart rate. The spirometry results showed severe bronchial obstruction in group1 (FEV1 49.973 $\pm 5.303 \%$ ) and group2 (FEV1 44.58 \pm 7.45) and no ventilation effectiveness impairment, in the control group, it was statistically significant. PASP was higher for group 3 compared with groups 1 and 2 , and was higher for group 2 compared with group 1, and this was statistically significant.

Table (2): Clinical characteristics, spirometry and PASP in COPD patients and control group

\begin{tabular}{|c|c|c|c|c|}
\hline Variables & Control(group 1) & $\begin{array}{l}\text { COPD without } \\
\text { (group 2) }\end{array}$ & $\begin{array}{l}\text { COPD with } \\
(\text { group 3) }\end{array}$ & p value \\
\hline Age(years) & $61.47 \pm 7.47$ & $62.87 \pm 7.26$ & $61.47 \pm 7.47$ & $0.7(\mathrm{NB})$ \\
\hline Male $(\%)$ & $25(83.33)$ & $25(83.33)$ & $25(83.33)$ & $1(\mathrm{NB})$ \\
\hline Female (\%) & $5(16.67)$ & $5(16.67)$ & $5(16.67)$ & $1(\mathrm{NB})$ \\
\hline HR(beat/min) & $81.27 \pm 5.93$ & $95.47 \pm 5.89$ & $107.73 \pm 6.9$ & $<0.001$ \\
\hline $\mathrm{FEV}_{1} \%{ }^{\#}$ & $93.1 \pm 5.268$ & $49.973 \pm 5.303$ & $44.58 \pm 7.45$ & $<0.001$ \\
\hline $\mathrm{FEV}_{1} / \mathrm{FVC}^{\beta}{ }^{\beta}$ & $84.7 \pm 1.841$ & $66.25 \pm 8.15$ & $55.15 \pm 8.02$ & $<0.001$ \\
\hline $\operatorname{PASP}(\mathrm{mmHg})^{¥}$ & $20.487 \pm 1.853$ & $24.267 \pm 4.025$ & $56.933 \pm 4.813$ & $<0.001$ \\
\hline
\end{tabular}

${ }^{*}$ p value $<0.001$ between group 1 and 2 , group 1 and 3 , and group 2 and 3 .

${ }^{\#} \mathrm{p}$ value $<0.001$ between group 1 and 2 , group 1 and 3 , and 0.003 between group 3 .

${ }_{\mathrm{p}} \mathrm{p}$ value $<0.001$ between group 1 and 2 , group 1 and 3 , and group 2 and 3 .

$¥ \mathrm{p}$ value $<0.001$ between group 1 and 3 , group 1 and 2 , and 0.001 between group 1 and 2 .

DOI: $10.9790 / 0853-15080691109 \quad$ www.iosrjournals.org $96 \mid$ Page


The data is presented as mean \pm standard deviation. Abbreviations: forced expiratory volume in one second FEV1, FEV1/VC\% - forced expiratory volume in one second /vital capacity ratio, HR (beat/min) heart rate per minute, NS - statistically no significant.

Incidence of pulmonary hypertension in COPD patients is.67.7\% of COPD patients had moderate PH and $33.3 \%$ had severe PH.The left ventricular diastolic function parameters in studied groups are shown in table (3). Conventional LV diastolic function parameters (A, E/A, and deceleration time of E) were impaired for groups 2 and 3 compared with group 1. Mitral early diastolic and late diastolic annular velocities ratio (Em/Am), were significantly lowest in COPD patients with $\mathrm{PH}$, and the isovolumetric relaxation time (IVRT) was significantly longer in group 3 and group 2 in relation to control group.

Table (3): Echocardiographic parameters of LV diastolic function in COPD patients groups and in control

\begin{tabular}{|c|c|c|c|c|}
\hline Variables & Control(group1) & $\begin{array}{l}\text { COPD without } \\
\text { (group 2) }\end{array}$ & $\begin{array}{l}\text { COPD with PH (group } \\
\text { 3) }\end{array}$ & p value \\
\hline $\mathrm{E}(\mathrm{cm} / \mathrm{s})$ & $65.87 \pm 5.42$ & $65.27 \pm 7.02$ & $62.87 \pm 4.75$ & .112 \\
\hline $\mathbf{A}(\mathrm{cm} / \mathrm{s})^{¥}$ & $62.03 \pm 5.07$ & $86.37 \pm 7.08$ & $81.43 \pm 4.55$ & $<.001$ \\
\hline E/A & $1.06 \pm 0.04$ & $0.75 \pm 0.02$ & $0.77 \pm 0.03$ & $<.001$ \\
\hline DT $(\mathrm{ms})^{\$}$ & $203.23 \pm 19.6$ & $275 \pm 19.4$ & $322.5 \pm 10.2$ & $<.001$ \\
\hline IVRT $(\mathrm{ms})^{\$}$ & $71.2 \pm 5.51$ & $102.27 \pm 4.45$ & $105.43 \pm 4.21$ & $<.001$ \\
\hline $\mathbf{E m} / \mathbf{A m}$ & $1.08 \pm 0.08$ & $0.8 \pm 0.07$ & $0.77 \pm 0.066$ & $<.001$ \\
\hline
\end{tabular}

${ }^{¥} \mathrm{p}$ value $<.001$ between group 1 and 2 , group 1 and $3, .003$ between group 2 and 3

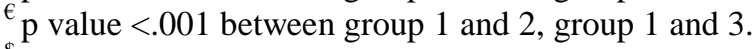

$\$ \mathrm{p}$ value $<.001$ between group 1 and 2 , group 1 and 3 , group 2 and 3 .

The right ventricular diastolic function parameters in studied groups are shown in table (4). E/A ratio were higher in the control subjects compared with the patient groups. The tricuspid inflow velocities ratio (E/A) was significantly lowest value in COPD patients with PH and the isovolumetric relaxation time (IVRT) was significantly longer in group 3 and group 2 in relation to control group.

Table (4): Echocardiographic parameters assessing RV diastolic function in COPD patients groups and in control group.

\begin{tabular}{|c|c|c|c|c|}
\hline Variables & Control (group 1) & $\begin{array}{l}\text { COPD without PH (group } \\
\text { 2) }\end{array}$ & COPD with PH (group 3) & p value \\
\hline $\mathrm{E}(\mathrm{cm} / \mathrm{s})^{\$}$ & $45.93 \pm 4.14$ & $50.5 \pm 8.8$ & $35.8 \pm 6.64$ & $<.001$ \\
\hline $\mathbf{A}(\mathbf{c m} / \mathbf{s})^{* *}$ & $33.83 \pm 4.15$ & $54.5 \pm 8.8$ & $42.57 \pm 5.78$ & $<.001$ \\
\hline E/A & $1.36 \pm 0.06$ & $0.92 \pm 0.01$ & $0.84 \pm 0.04$ & $<.001$ \\
\hline IVRT(ms) & $75.37 \pm 5.2$ & $77.5 \pm 4.57$ & $98.87 \pm 8.41$ & $<.001$ \\
\hline
\end{tabular}

$\$$ p value <.001 between group 1 and 3, group 2 and 3, and .027 between group 1 and 2.

* $\mathrm{p}$ value $<.001$ between group 1 and 3 , and group 2 and 3 .

p value <.001 between group 1 and 2, group 1 and 3, and group 2 and 3.

The analysis of systolic function parameters of LV (FS\%, EF \%), interventricular septum thickness in diastole (IVSd), LV dimensions and left ventricular mitral valve annular velocity ( $\left.\mathrm{S}^{\prime}\right)$ in studied groups are shown in table (5). LV end-diastolic diameter was significantly lower for group 3 than group 1and group 2. Left ventricular mitral valve annular velocity $\left(\mathrm{S}^{\prime}\right)$ was lowest in goup3and was in the normal value range. However, conventional systolic function parameters and IVSd were not different among the groups.

Table (5): Echocardiographic parameters assessing the LV dimensions, systolic function, interventricular septum thicknessin each group.

\begin{tabular}{|l|l|l|l|l|}
\hline Variables & Control (group 1) & $\begin{array}{l}\text { COPD without PH } \\
\text { (group 2) }\end{array}$ & COPD with PH (group 3) & p value \\
\hline LVESD(mm) & $27.7 \pm 2.168$ & $27.367 \pm 3.379$ & $26.267 \pm 3.433$ & \\
\hline LVEDD, (mm) & $46.2 \pm 2.295$ & $44.2 \pm 3.367$ & $40 \pm 2.665$ & $>.05$ \\
\hline LV FS\% & $38.13 \pm 2.01$ & $37 \pm 2.78$ & $36.27 \pm 4.21$ & $<.001$ \\
\hline LV EF\% & $68.33 \pm 2.01$ & $66.12 \pm 2.78$ & $67.44 \pm 3.21$ & $>.05$ \\
\hline S' $^{\prime}\left(\mathrm{cm} / \mathbf{s}^{+}{ }^{+}\right.$ & $10.66 \pm 0.46$ & $10.76 \pm 0.62$ & $9.64 \pm 0.92$ & $>.05$ \\
\hline
\end{tabular}




\begin{tabular}{|l|l|l|l|l|}
\hline IVSd (mm) & $10.16 \pm 0.96$ & $10.44 \pm 0.57$ & $10.1 \pm 0.66$ & $>.05$ \\
\hline
\end{tabular}

${ }^{\alpha} \mathrm{p}$ value $<.001$ between group 1 and 3, between group 2 and 3, and .019 between group 1 and 2.

${ }^{+} \mathrm{p}$ value <.001 between group 1 and 3 , and group 2 and 3 .

Systolic function parameters of RV (FS\%, EF \%), right ventricular free wall thickness, RV dimensions, right ventricular tricuspid valve annular velocity $\left(S^{\prime}\right)$ and TASE in studied groups are shown in table (6). Systolic and diastolic RV diameters were higher and RV fractional shortening was lower for group 3 than the other two groups. TAPSE was significantly lower for group 3 compared with group 1 and group2, but differences between groups 1 and 2 was not statistically significant. RV wall thickness was significantly high in patients with $\mathrm{PH}$ and without $\mathrm{PH}$ and was normal in control group.

Table (6): Echocardiographic parameters assessing the right ventricular dimensions, systolic function, and right ventricular free wall thickness in each group.

\begin{tabular}{|c|c|c|c|c|}
\hline Variables & Control (group 1) & $\begin{array}{l}\text { COPD without } \\
\text { (group 2) }\end{array}$ & $\begin{array}{l}\text { COPD with PH (group } \\
\text { 3) }\end{array}$ & p value \\
\hline $\operatorname{RVESD}(\mathrm{mm})^{*}$ & $21.38 \pm 2.01$ & $20.9 \pm 2.86$ & $29.73 \pm 7.16$ & $<.001$ \\
\hline RVEDD $(\mathbf{m m}){ }^{*}$ & $30.27 \pm 1.95$ & $30.9 \pm 2.86$ & $38.17 \pm 6.64$ & $<.001$ \\
\hline RVWT(mm) ${ }^{\text {s }}$ & $3.64 \pm 0.66$ & $6.5 \pm 0.85$ & $7.52 \pm 0.76$ & $<.001$ \\
\hline RV FS\% ${ }^{* * *}$ & $29.43 \pm 2.6$ & $32.5 \pm 2.99$ & $23.1 \pm 5.9$ & $<.001$ \\
\hline RV EF\% & $65.27 \pm 4.32$ & $69.4 \pm 4.22$ & $53.53 \pm 10.14$ & $<.001$ \\
\hline$S^{\prime}(\mathrm{cm} / \mathrm{s})^{\$ \$}$ & $10.81 \pm 1.86$ & $10.66 \pm 0.62$ & $9.54 \pm 0.92$ & $<.001$ \\
\hline TAPSE $(\mathbf{m m})^{*}$ & $21.7 \pm 2.71$ & $20.83 \pm 2.69$ & $16.07 \pm 3.54$ & $<.001$ \\
\hline
\end{tabular}

${ }^{*} \mathrm{p}$ value $<.001$ between group 1 and 3 , and group 2 and 3 .

p value $<.001$ between group 1 and 3 , group 2 and 3 , and .013 between group 1 and 2 .

$\$ \$$ value .001 between group 1 and 3 , and .002 between group 2 and 3.

$\$ \mathrm{p}$ value $<.001$ between group 1 and 2 , group 1 and 3 , and group 2 and 3

Echocardiographic parameters assessing the left ventricle MPI in each group are shown in table (7).IVRTm was significantly longer for group 3compared with gruop1 and group 2 but difference of this parameter between groups 1 and control group was not statistically significant. ETm was shorter in group 3 than in group 1 and shorter in group 2 than group1, but difference between groups 3 and 2 was not statistically significant. IVCTm was not different among the groups. There was statistical difference between values of LVMPI of control and patient groups and was higher for group 3 compared with groups 1 and 2. Difference between groups 1 and 2 was also significant.

Table (7): Echocardiographic parameters assessing the left ventricle MPI in each group.

\begin{tabular}{|c|c|c|c|c|}
\hline Variables & Control (group 1) & $\begin{array}{l}\text { COPD without } \\
\text { (group 2) }\end{array}$ & $\begin{array}{l}\text { COPD with PH (group } \\
\text { 3) }\end{array}$ & p value \\
\hline IVRTm(ms) ${ }^{* * *}$ & $93.67 \pm 7.54$ & $96.83 \pm 12.65$ & $130.07 \pm 10.28$ & $<.001$ \\
\hline IVCTm(ms ) & $59.77 \pm 6.25$ & $60 \pm 7.52$ & $63.63 \pm 9.52$ & .109 \\
\hline $\operatorname{Em}(\mathbf{m s}){ }^{*}$ & $306.83 \pm 7.9$ & $278.27 \pm 18.1$ & $268.57 \pm 14.2$ & $<.001$ \\
\hline LV MPI $^{\$ \$}$ & $0.5 \pm 0.034$ & $0.56 \pm 0.037$ & $0.7 \pm 0.083$ & $<.001$ \\
\hline
\end{tabular}

${ }^{* *} \mathrm{p}$ value $<.001$ between group 1 and 3 , and group 2 and 3 .

${ }_{* * *} \mathrm{p}$ value $<.001$ between group 1 and 2 , and between 1 and 3 , and 0.024 between 2 and 3

$\$ \$ \mathrm{p}$ value $<.001$ between group 1 and 2 , group 1 and 3 , and group 2 and 3.

Echocardiographic parameters assessing the right ventricle MPI in each group are shown in table(8). Doppler tissue-derived IVRTt was longer for group 3 compared with groups 1 and 2, and was longer for group 2 compared with group 1. Difference of IVCTt among the groups was not significant. ETt was lower in both groups 2 and 3 than in group 1and lower in group 3 compared with group 2. As a result of differences in these time intervals, RVMPI was higher in group 3 compared with groups 1 and 2, and was higher for group 2 compared with group 1.

Table (8): Echocardiographic parameters assessing the right ventricle MPI in each group.

\begin{tabular}{|l|l|l|l|l|}
\hline Variables & Control (group 1) & $\begin{array}{l}\text { COPD without PH } \\
\text { (group 2) }\end{array}$ & $\begin{array}{l}\text { COPD with PH (group } \\
\text { 3) value }\end{array}$ & p \\
\hline IVRTt(ms) $^{\$ \$ \$}$ & $47.97 \pm 6.5$ & $\mathbf{5 8 . 8} \pm \mathbf{1 7 . 2 4}$ & $\mathbf{9 8 . 8 7} \pm \mathbf{8 . 4 1}$ & $<.001$ \\
\hline IVCTt(ms) $^{*}$ & $\mathbf{6 6 . 3} \pm \mathbf{9 . 0 3}$ & $\mathbf{6 7 . 5} \pm \mathbf{1 6 . 8 6}$ & $\mathbf{6 8 . 0 3} \pm \mathbf{8 . 7 3}$ & $>.05$ \\
\hline ETt(ms) ${ }^{* *}$ & $\mathbf{2 7 1 . 3} \pm \mathbf{1 0 . 6 8}$ & $\mathbf{2 1 7 . 1 7} \pm 16.71$ & $\mathbf{2 0 3 . 5 7} \pm \mathbf{8 . 0 8}$ & $<.001$ \\
\hline RVMPI $^{* *}$ & $\mathbf{0 . 4 2} \pm \mathbf{0 . 0 4 3}$ & $\mathbf{0 . 5 7} \pm \mathbf{0 . 1 1}$ & $\mathbf{0 . 9 6} \pm \mathbf{0 . 0 5}$ & $<.001$ \\
\hline
\end{tabular}


${ }^{*} \mathrm{p}$ value $<.001$ between group 1 and 3 , and group 2 and 3.

** $\mathrm{p}$ value <.001 between group 1 and 2 , group 1 and 3 , and group 2 and 3.

$\$ \$$ p value <.001 between group 1 and 3, group 2 and 3, and .002 between group 1 and 2 .

Comparison of the LVMPI and RVMPI among the groups is illustrated in figure 1.There LVMPI and RVMPI were higher in group 3 compared with groups 1 and 2, and were higher for group 2 compared with group 1.Differences between group1 and 2 , group 1 and 3 and group 2 and 3 were statistically significant for both LVMPI and RVMPI.

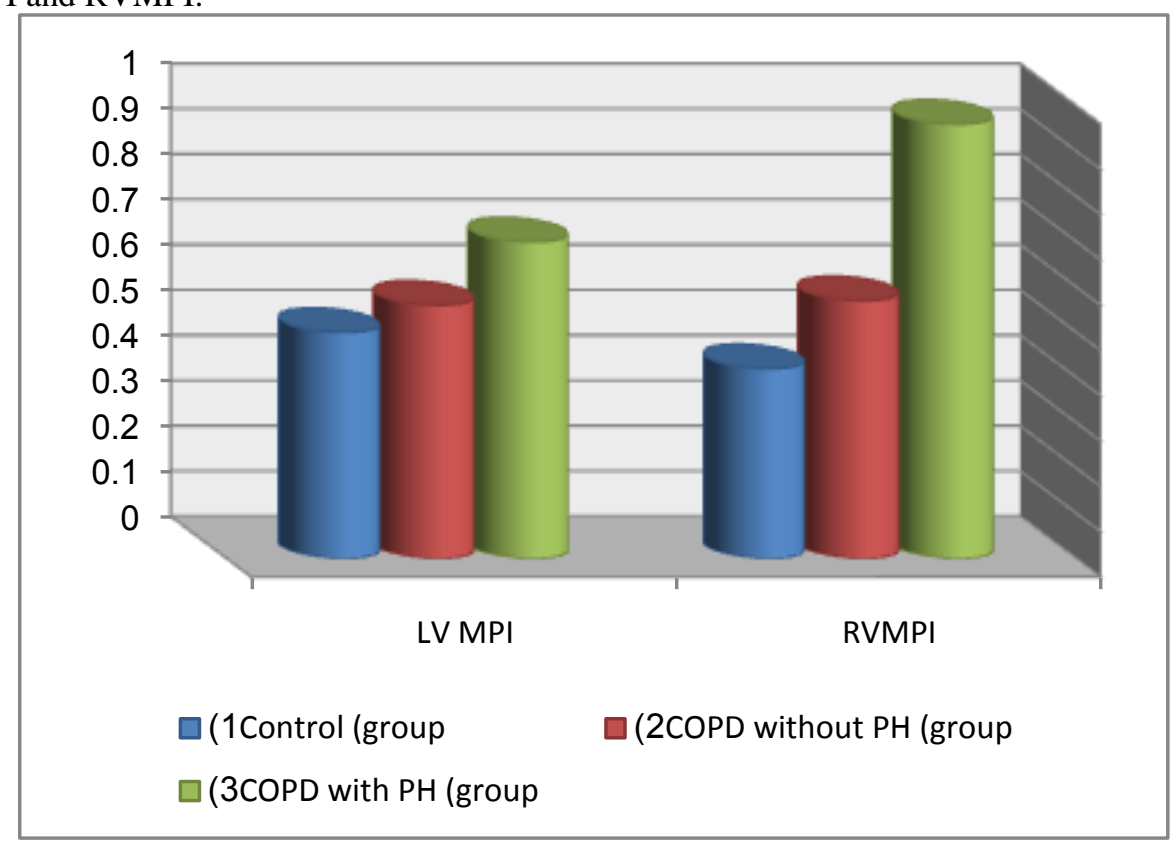

Figure (1): Comparison of left ventricle myocardial performance index (LVMPI) and right ventricle myocardial performance index $(R V M P I)$ among control subjects, patients with chronic obstructive pulmonary disease $(C O P D)$ without $P H$, and those with COPD with $\mathrm{PH}$.

Age, HR, PASP, RVMPI were directly correlated with LVMPI, while FEV F $_{1}$ and TAPSE were inversely correlated with LVMPI when univariate linear correlation was used that was performed by including the patients in groups 2 and 3. When multiple linear regression was used to assess whether these variable were independently correlated, only $\mathrm{FEV}_{1}$ and RVMPI were found to be independently correlated with beta $=1.133, \mathrm{p}$ $=0.007$ and beta $=1.436, \mathrm{p}=0.009$ respectively. Table (9).

Table (9)Univariate and multivariate relationships of clinical and right ventricular echocardiographic indexes to LVMPI in patients with PH

\begin{tabular}{|l|l|l|l|l|l|}
\hline Variable & $\begin{array}{l}\text { Person correlation } \\
\text { coefficient }\end{array}$ & P value & $\begin{array}{l}\text { Standardized beta } \\
\text { regression coefficient }\end{array}$ & P value & $\begin{array}{l}\text { Partial correlation } \\
\text { coefficient }\end{array}$ \\
\hline Age & .944 & $<.0001$ & .474 & .221 & .254 \\
\hline HR & .961 & $<.0001$ & .402 & .234 & .247 \\
\hline FEV $V_{1}$ & $\mathbf{. 9 2 6}$ & $<.0001$ & 1.133 & .007 & .525 \\
\hline TAPSE & $\mathbf{. 9 5 7}$ & $<.0001$ & -.548 & .146 & .299 \\
\hline PASP & .940 & $<.0001$ & -.758 & .128 & .312 \\
\hline RVMPI & .943 & $<.0001$ & 1.436 & .009 & .513 \\
\hline
\end{tabular}

Comparison between moderate and severe COPD show significant difference regarding LV Systolic function $\left(E F, S^{\prime}\right)$ and diastolic function (E,E/A, Em/Am, IVRT), also LV global function(LVMPI) show significant difference between moderate and severe COPD. There was statistical significant difference between moderate and severe COPD regarding RV systolic function (EF) and RV diastolic (E, E/A) but there was no significant difference regarding RV global function. Table (10).

Table10: Statistical comparison between moderate and severe grades of COPD patients in echocardiographic findings

\begin{tabular}{|l|l|l|l|}
\hline Variable & Moderate & Severe & P value \\
\hline LV systolic function & & \\
\hline
\end{tabular}


Assessment Of Left And Right Ventricular Functions By Myocardial Performance Index In ..

\begin{tabular}{|c|c|c|c|}
\hline EF\% & $74.29 \pm 3.24$ & $66.46 \pm 4.34$ & $<.001 *$ \\
\hline $\mathbf{S} \square(\mathbf{c m} / \mathbf{s})$ & $10.685 \pm 0.686$ & $9.569 \pm 0.904$ & $<.001 *$ \\
\hline \multicolumn{4}{|c|}{ LV diastolic function } \\
\hline $\mathrm{E}(\mathrm{cm} / \mathrm{s})$ & $68.03 \pm 4.01$ & $58.88 \pm 4.02$ & $<.001 *$ \\
\hline E/A & $0.7835 \pm 0.0233$ & $0.7350 \pm 0.0130$ & $<.001 *$ \\
\hline $\mathbf{E m} / \mathbf{A m}$ & $0.8329 \pm 0.0395$ & $0.7200 \pm 0.0485$ & $<.001 *$ \\
\hline IVRT(ms) & $101.15 \pm 2.62$ & $107.38 \pm 4.19$ & $<.001 *$ \\
\hline \multicolumn{4}{|c|}{ LV global function } \\
\hline LV MPI & $0.6097 \pm 0.0791$ & $0.684 \pm 0.117$ & $<.001 *$ \\
\hline \multicolumn{4}{|c|}{ RV systolic function } \\
\hline RV EF\% & $64.74 \pm 9.74$ & $57.2 \pm 11.5$ & $0.008^{*}$ \\
\hline \multicolumn{4}{|c|}{ RV diastolic function } \\
\hline $\mathbf{E}(\mathbf{c m} / \mathbf{s})$ & $47.4 \pm 10.5$ & $37.54 \pm 7.99$ & $<.001 *$ \\
\hline E/A & $0.8956 \pm 0.0376$ & $0.8600 \pm 0.0671$ & 0.012 * \\
\hline IVRT(ms) & $84.2 \pm 11.4$ & $91.0 \pm 15.7$ & $0.057^{\#}$ \\
\hline \multicolumn{4}{|c|}{ RV global function } \\
\hline RVMPI & $0.731 \pm 0.230$ & $0.812 \pm 0.178$ & $0.145^{\#}$ \\
\hline
\end{tabular}

The parameters of Age, HR, PASP and RVMPI in patients without PH there were found to be not independently correlated with LVMPI, table (11).

Table (11)Univariate and multivariate relationships of clinical and right ventricular echocardiographic indexes to LVMPI in patients without PH

\begin{tabular}{|l|l|l|l|l|l|}
\hline Variable & $\begin{array}{l}\text { Person correlation } \\
\text { coefficient }\end{array}$ & P value & $\begin{array}{l}\text { Standardized beta } \\
\text { regression } \\
\text { coefficient }\end{array}$ & P value & $\begin{array}{l}\text { Partial correlation } \\
\text { coefficient }\end{array}$ \\
\hline Age & -.197 & .153 & -.052 & .236 & -.252 \\
\hline HR & .419 & .012 & -.17 & .427 & -.17 \\
\hline FEV & -.46 & .006 & -.072 & .738 & -.072 \\
\hline TAPSE & $\mathbf{- . 9 7 5}$ & $<.001$ & -.503 & .085 &.- .359 \\
\hline PASP & .963 & $<.001$ & -.222 & .629 & -.104 \\
\hline RVMPI & .974 & $<.001$ & .735 & .15 & .303 \\
\hline
\end{tabular}

Finally forward selection procedure was done to evaluate RV indexes and pulmonary function predictors to evaluate LVMPI, the parameter with associated with good prediction of LVMPI in patients with PH were: $\mathrm{FEV}_{1} \%$, RVFS, RVEF, E/A, IVRT, S', IVRTt, IVCTt, and PASP

An important correlation between the LV parameters (mitral inflow velocities ratio (E/A), mitral early diastolic and late diastolic annular velocities ratio (Em/Am), and the isovolumetric relaxation time (IVRT)) and the right ventricular pressure was found in COPD patients with pulmonary hypertension. The strongest inverse correlation was observed between (PASP) and the mitral valve annular velocities Em/Am ratio in patients with $\mathrm{PH} ; \mathrm{r}=-0.947, \mathrm{p}=<0.001$ (fig. 2A). A weaker negative correlation was observed between PASP and the mitral valve inflow velocities (E/A) ratio in patients with $\mathrm{PH} ; \mathrm{r}=-0.889, \mathrm{p}=<0.001$ (fig. $2 \mathrm{~B}$ ). The weakest, but still important, correlation was observed between PASP and the isovolumetric relaxation time in patients with PH (IVRT; $r=0.674, p=<0.001)($ figure2C).

A)

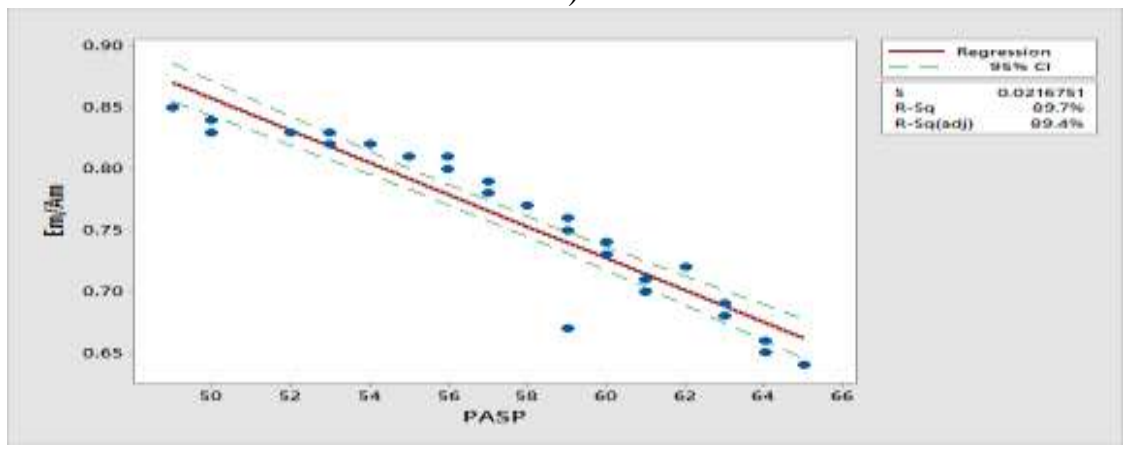

B) 


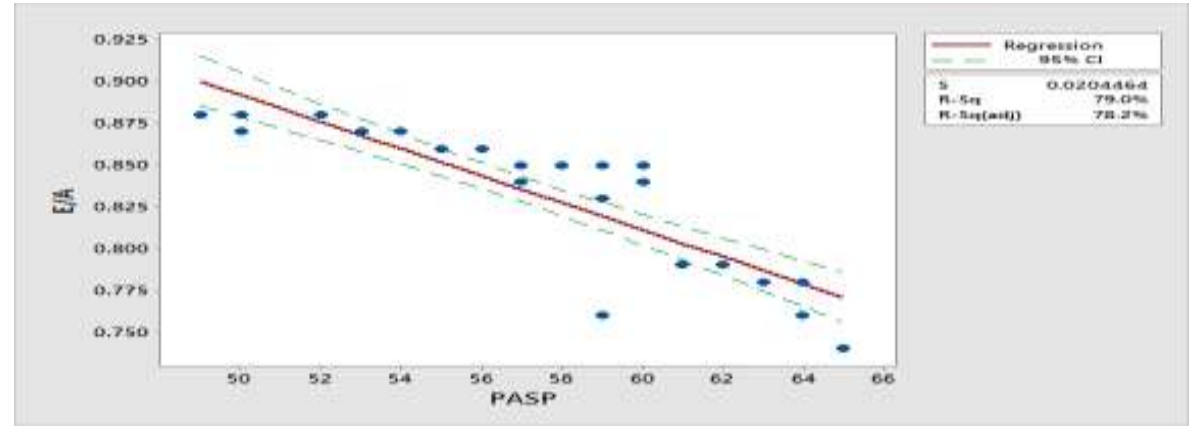

C)

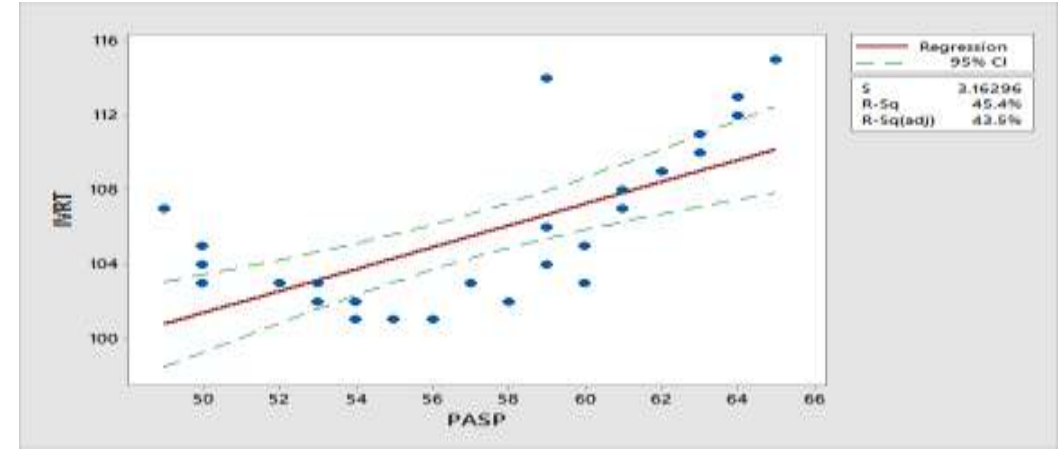

Figure 2: Correlation between the LV parameters A) mitral inflow velocities ratio (E/A),B) mitral early diastolic and late diastolic annular velocities ratio (Em/Am), and $\mathrm{C}$ ) the isovolumetric relaxation time (IVRT)) and the right ventricular pressure in COPD patients with pulmonary hypertension.

\section{VI.Discussion}

The influence of the right ventricular volume or pressure overload on the left ventricular function is known as the reverse Bernheim phenomenon, and is associated with the existence of a common wall such as the interventricular septum, and the common pericardium holding the cavities of the heart. ${ }^{(1)}$ In the case of right ventricular long-standing pressure overload the dominant role is played by the interventricular septum shift into the left ventricular cavity and this may result in the limitation of left ventricular cavity dimensions, its contractility and compliance and in consequence in the rise of the left ventricular diastolic pressure. ${ }^{(96,97)}$ This phenomenon has been described in detail with respect to patients with severe primary pulmonary arterial hypertension. ${ }^{(97)}$

The present work included 50 male $(83.3 \%)$ and 10 female patients $(16.7 \%)$ and 30 control subjects. The mean age of included patients was $62.9 \pm 7.3$ years.

In the present study, 30 COPD patients (50\%) had pulmonary hypertension and 30(50\%) COPD patients without $\mathrm{PH}$.

The difference between COPD patients and control group as regarding age and gender was statistically non-significant. In the studied COPD patients, $34(56.7 \%)$ had moderate disease and 26(43.3\%) had severe disease.

In the present study, by comparing echocardiographic findings in COPD patients with and without pulmonary hypertension and control group, heart rate was different among the groups, there was a highly statistically significant difference in heart rate between COPD patients and control group, and it also increased significantly with COPD patients with pulmonary hypertension. This could be explained by the effect of hypoxia and hypercapnea as stimulants to the sympathetic system, by the frequent association of autonomic neuropathy in COPD as the parasympathetic activity was found to be significantly reduced in COPD, while there was sympatho excitation, and finally as a side effect to the COPD medications as bronchodilators. ${ }^{(98,98)}$. However, the MPI is not greatly influenced by changes in heart rate. ${ }^{(100)}$ On the other hand, Doppler derived isovolumic relaxation and contraction times, and ejection time, have been shown to be dependent on heart rate. ${ }^{(101,102,103,104)}$ Because of this, these intervals were adjusted for heart rate in our study. Other study shows that heart rate $(\mathrm{HR})$ in the COPD patients did not significantly differ from control group. ${ }^{(105)}$

In the present study, echocardiographic assessment of left ventricular systolic function in COPD patients was in the normal value range and revealed a non significant difference from control group. Similar results were obtained by other investigators (Schena M, et al. and Marcus T, et al.). ${ }^{(106,107)}$ As suggested in the bibliography, in the absence of conditions primarily leading to left ventricular systolic function impairment, the derangement 
of systolic function in the course of COPD is rarely found, usually in severe pulmonary hypertension, in patients with right ventricular dysfunction. ${ }^{(108,109)}$

In the present work, left ventricular systolic function significantly differ between moderate and severe grades of COPD. patients. ${ }^{(110)}$

Some investigators, however, suggest the presence of subclinical systolic dysfunction in the COPD Suchon' et al. ${ }^{(105)}$ found that ejection fraction, shortening fraction and lateral mitral annular peak systolic velocity in COPD patients, were in the normal value range and did not differ significantly from control group. Similar results were obtained by other investigators. ${ }^{(111,112)}$ On the other hand, Gupta et al. ${ }^{(113)}$, in their study, found that left ventricular systolic dysfunction (LVSD) was present in 7.5\% of COPD patients.

Regarding RV systolic function, small increases in pulmonary artery pressure may result in large increases in $\mathrm{RV}$ work, because RV is thin-walled and eccentric. PH overloads the RV, enlarges right heart chambers, and ultimately causes RV failure. ${ }^{(114)}$ In our study, patients with PH had larger RV diameters than patients without $\mathrm{PH}$ and control subjects.

TAPSE, a validated measure of RV longitudinal shortening, ${ }^{(115)}$ has been used to explore RV systolic dysfunction in different cardiac diseases. ${ }^{(16,117)}$ In the our study, no significant TAPSE difference was observed between the COPD group without PH and the control group. Nevertheless, TAPSE distinguished the COPD group with PH and the control group, as it was significantly lower in the presence of PH in patients with COPD. Similarly, RV fractional shortening was also lower in those with PH but not in those without PH compared with control subjects. These findings suggest that the development of impaired RV systolic function is more likely to be the consequence of higher levels of PH, rather than the result of COPD alone.

The main finding of this study was the high prevalence of mild left diastolic dysfunction in COPD patients, which was associated with increased disease severity.

The results presented in this study clearly indicate the impaired diastolic function in the studied patient group and show significant difference among groups regarding left ventricular diastolic function (E wave peak velocity by mitral flow, E wave peak velocity by DTI, Em/Am ratio by DTI, Eflow/Aflow ratio by mitral flow, isovolumetric relaxation time IVRT) and left ventricular global function (myocardial performance index).

Lamia et al. ${ }^{(118)}$ found that the E wave was significantly lower and the A wave was significantly higher in COPD patients compared to control subjects. The E/A ratio was significantly lower in COPD patients as well as the Em velocity, indicating a LV diastolic dysfunction. They concluded that LV diastolic dysfunction does exist in COPD patients with increased RV afterload and no pre-existing LV dysfunction.

In the present study, by comparing echocardiographic findings in COPD patients with and without pulmonary hypertension and control group, There was a highly statistically significant difference among groups in mitral Em/Am ratio (measured by DTI) and a statistically significant difference in mitral E/A ratio (measured by flow) and myocardial performance index .

In our study ,left ventricular diastolic function assessment revealed a statistically significant difference in $\mathrm{E}$ wave peak velocity, E/A ratio and Em/Am ratio between moderate vs. severe COPD grades. Also, isovolumetric relaxation time (IVRT) was significantly shorter in moderate vs. severe COPD patients. Left ventricular global function measured by myocardial performance index (MPI) was significantly different between moderate vs. severe COPD grades. The development of relaxation diastolic dysfunction is most probable in patients with severe pulmonary hypertension as shown in this study.

Moreover, there was a strong correlation between the level of impairment of diastolic function and the level of pressure in the pulmonary artery which correlates with other investigators findings. ${ }^{(119,120)}$ Tutar et al (121) described the left ventricular diastolic function impairment in COPD patients, and a similar correlation between right ventricular pressure and E/A ratio, and IVRT. Schena et al ${ }^{(5)}$ also demonstrated that the right ventricular pressure correlates with left ventricular eccentricity indexes; the distorted ventricular geometry results in its abnormal filling pattern in turn. The relation between right ventricular pressure and left ventricular diastolic dysfunction in a large group of corpulmonale patients of different etiology (including COPD patients), was confirmed by Mustapha et al. ${ }^{(122)}$

Funk et al. ${ }^{(123)}$ found LV diastolic dysfunction (LVDD) in COPD patients with normal pulmonary arterial pressure and it increased with right ventricular afterload. Moreover, Gupta et al. ${ }^{(113)}$, found LVDD in $47.5 \%$ of patients, out of which 16 patients had $\mathrm{PH}$ and 3 did not have $\mathrm{PH}$, various mechanisms might explain the presence of left ventricular diastolic dysfunction in COPD patients. This may be due to chronic hypoxemia leading to abnormalities of myocardial relaxation, lung hyperinflation and distension leading to increased stiffness of the parietal pleura and thus of the wall of cardiac fossa leading to added load on ventricle, and also due to ventricular interdependence.

Moreover, Barasch et al. ${ }^{(124)}$ found a quantitative relationship between the severity of pulmonary hypertension and LV diastolic function. They explained LV diastolic dysfunction in the presence of pulmonary hypertension by abnormal geometrical configuration and motion of interventricular septum, presence of some 
degree of LV interstitial edema, which increases the LV wall stiffness and alters its normal diastolic filling ${ }^{(125)}$ and the diastolic asynchrony found in the apical and lateral walls. ${ }^{(126)}$ Also, Mustapha et al. ${ }^{(122)}$ found that LV diastolic dysfunction of impaired relaxation type is most commonly seen in patients with severe $\mathrm{PH}$ but not in mild and moderate $\mathrm{PH}$ and mentioned that SPAP $\geq 60 \mathrm{mmHg}$ is needed to induce changes in the LV diastolic filling pattern.

In addition, the hypothesis that an abrupt reduction in pulmonary artery pressure in patients with chronic pulmonary hypertension results in an early improvement of left ventricular diastolic function was studied by Dittrich et al. ${ }^{(127)}$ Kasner et al. ${ }^{(128)}$ studied LV function in patients with non severe idiopathic pulmonary arterial hypertension (IPAH). They found that idiopathic pulmonary arterial hypertension impairs LV diastolic function even in the absence of intrinsic LV disease. Bhargava and Sunnerhagen ${ }^{(129)}$ found left ventricular regional wall motion early diastolic asynchrony in 11 patients with pulmonary hypertension. They explained that by the interventricular interaction caused by pressure gradients across the septum. Gan et al. ${ }^{(130)}$ found that stroke volume, left ventricular end-diastolic volume and left ventricular peak filling rate were decreased in PH patients compared with control subjects. They concluded that there is an impaired left ventricular filling due to right-to-left ventricular interaction in patients with pulmonary arterial hypertension.

The analysis of RV diastolic function was performed by measuring Doppler tricuspid inflow and IVRTt, which showed the typical pattern of impaired RV relaxation. RV diastolic dysfunction was present in the patients with COPD with and without $\mathrm{PH}$. There are inconsistent reports in the literature regarding RV diastolic dysfunction in patients with COPD without PH. ${ }^{(131,132,133)}$ In a study by Caso et al, ${ }^{132}$ it was found that RV diastolic dysfunction was present in patients with COPD without PH. Our results are consistent with that study. Right ventricular dysfunction-can lead to deterioration of LV performance. Intra-thoracic pressure varies widely in patients of COPD leading to increase in pulmonary artery pressure, RV overload and venous return to the right side of the heart. Together, these alterations lead to RV distension, distortion of interventncular septum and impairment of LV function. ${ }^{(134)}$

In the present work, LV global function measured by myocardial performance index (MPI) (also called TEI index) differed significantly between COPD patients with and without pulmonary hypertension and control group. Similar results were obtained by other investigators. ${ }^{(135)}$

Although LV diastolic dysfunction has been shown in patients with COPD, this study evaluated LVMPI as a marker of both systolic and diastolic LV functions in this patient group. Patients with COPD with PH had abnormal Doppler time intervals, comprised of prolonged IVRTm and shortened ETm, resulting in a significant increase in LVMPI. This increase was significant versus both control subjects and patients without PH. Nevertheless, although LVMPI of the patients with COPD without PH was slightly higher than control subjects, this difference was not significant. Although patients with COPD with PH had normal LV EF and LV fractional shortening, the LVMPI was beyond the control subjects' levels. The LVMPI has been shown to be better than LV EF in predicting the prognosis and survival. ${ }^{(136},{ }^{137},{ }^{138)}$ Therefore, the increased LVMPI with normal LV EF in patients with PH strongly suggests the presence of LV dysfunction. The elevation of the LVMPI for group 3 was not only caused by prolongation of IVRTm, but also differences of systolic time intervals. It is very important to suggest that, in our study, these LV systolic and diastolic abnormalities were related to severity of COPD, an increase of $\mathrm{PH}$, and deterioration of RV function as confirmed by independent and significant correlation between the LVMPI and FEV1, PASP, and RVMPI by multiple regression analysis. Conventional pulsed wave Doppler-derived MPI is proposed as a potentially useful predictor of systolic and diastolic cardiac function. ${ }^{(136,139,140,141,142)}$ However, there is an important limitation in that the interval between the end and the onset of mitral inflow, and ejection time is measured sequentially and not on the same cardiac cycle in this method. Because of this, results are probably less reliable in the presence of heart rate fluctuation even if normal in sinus rhythm is present. Pulsed wave Doppler tissue, as used in this study, can simultaneously record systolic and diastolic mitral annular velocities. Determination of MPI derived by pulsed wave Doppler tissue requires measurement of only two simple intervals on the same cardiac cycle. It is shown that MPI derived from the mitral annulus by pulsed wave Doppler tissue correlates well with MPI derived by conventional pulsed wave Doppler and can be used as a simple and reliable method for assessing LV myocardial performance even in the presence of heart rate fluctuation in patients with in sinus rhythm. ${ }^{(143,144)}$ Therefore, we used pulsed wave Doppler tissue in obtaining the MPI.

Regarding MPI of right ventricle which reflects both systolic and diastolic ventricular performance distinguished the global RV dysfunction in both patient with PH and without PH from the control subjects. Furthermore, difference between patient with PH and without PH was also demonstrated by RVMPI.Pulmonary hypertension is a common complication seen in patients with advanced chronic obstructive pulmonary disease (COPD). It has clear effects on both morbidity and mortality. Impairment of right ventricular function and increased pulmonary blood pressure are well known to complicate the clinical course of COPD and co-relate inversely with survival. ${ }^{(145)}$ 
Although the true prevalence of PH in COPD is unknown, an elevation of pulmonary arterial pressure is reported to occur in 20-90\% of patients when measured by right heart catheterization with some evidence that pulmonary hemodynamics worsen with worsening airflow obstruction. ${ }^{(146,147)}$ In our study, the incidence of PH was $36.7 \%$ in moderate COPD and $63.3 \%$ in severe COPD.Pulmonary hypertension in the course of COPD is usually of a mild or moderate grade ${ }^{(148,149)}$ however, that in this group of patients, a rapid pulmonary artery pressure rise may occur with light exercise or in the event of infectious exacerbations. ${ }^{(148,107)}$ The results of the present study show $66 \%$ of patients had moderate $\mathrm{PH}$ and $33 \%$ had severe $\mathrm{PH}$. In our study, the right ventricular pressure ranged from $49-65 \mathrm{mmHg}$; mean $56.9 \pm 4.8 \mathrm{~mm} \mathrm{Hg}$.

It is to be expected that the diastolic function impairment which increases proportionally to right ventricular rise in pressure, will substantially augment during physical exercise. It is therefore possible that apart from the respiratory tests results, and right ventricular performance the right ventricular diastolic performance, may play a major role in the clinical setting of the COPD. The potential rise in left ventricular filling pressure passively transmitted to the pulmonary, capillary vascular system, may add up to the already augmented precapillary pressure and cause dyspnea exacerbation in these patients.

Jupta et al. ${ }^{(150)}$ found that the frequencies of PH in mild, moderate, severe, and very severe COPD were $16.67 \%, 54.55 \%, 60.00 \%$, and $83.33 \%$, respectively. The effects of COPD and emphysema on the heart have long been recognized but have been studied principally in very severe COPD. ${ }^{(151)}$ Clinical data on pulmonary hypertension in milder lung disease are limited owing to the invasiveness of the usual reference measure, that is, right heart catheterization. A study involving patients with mild-to-moderate COPD that used right heart catheterization showed increases in pulmonary artery pressure with exercise. ${ }^{(152)}$ Anatomical studies showed proliferation of smooth-muscle cells in pulmonary arteries from patients with mild-to moderate COPD ${ }^{(153,154)}$ and from smokers without COPD, ${ }^{(155)}$ which suggests subclinical increases in pulmonary vascular resistance in patients with mild-to-moderate COPD and in smokers without spirometrically defined COPD. Barbera and Blanco ${ }^{(156)}$ found that the prevalence of PH is high in patients with advanced COPD, whereas in milder forms it might not be present at rest but may develop during exercise.

\section{VII.Limitations}

The main limitation of this study is the lack of PASP invasive hemodynamic measurement, which is the reference technique. Furthermore, simple standard Doppler-derived indexes (eg, acceleration time of RV outflow velocity profile), which have demonstrated close correlation with mean PASP measured by catheterization, ${ }^{(157)}$ were not estimated in this study. However, despite technical difficulty, Doppler- measured tricuspid regurgitation is widely used in the clinical setting for PH estimation, and the parasternal approach used to measure standard Doppler RV systolic time intervals is often unavailable in patients with COPD. Secondly, increasing of LVMPI may also be related to abnormal septal motion in patients with COPD. In this study, grouping of the patients was performed according to presence of PH rather than septal motion abnormality.

However, abnormality of septal motion is almost always related to increased pulmonary arterial pressure.

We should consider the major limitations of the present work, e.g., its small sample size and the recruitment of all patients from a single medical center. In addition, tissue Doppler imaging was not performed for evaluation of diastolic function.

\section{VIII.Conclusion}

Left ventricular diastolic function and LV global function are affected in COPD patients especially with progression of the disease. COPD patients with pulmonary hypertension are more liable to LV diastolic and global dysfunction than normal pulmonary pressure COPD patients. Doppler tissue echocardiography is a better tool than conventional methods in the assessment of left ventricular function.In conclusion, using Doppler tissue-derived LVMPI, we have demonstrated a marked impairment of both LV systolic and diastolic performance for patients with COPD and PH. This impairment is independently associated with FEV1, PASP, and RVMPI.COPD patients have a high prevalence of left ventricular diastolic dysfunction, which is associated with disease severity. Thus, because of this association, it is important to exclude decompensated heart failure during COPD exacerbation.

The left ventricular diastolic function in patients with advanced COPD is impaired. The level of diastolic impairment is proportional to the right ventricular pressure. Impairment of left ventricular systolic function has not found in COPD patients.

\section{IX.Recommendation}

This study has demonstrated LV dysfunction expressed as abnormal systolic and diastolic cardiac time intervals, even with the presence of normal EF. Therefore, the results have indicated the importance of careful estimation and follow-up of LV function in patients with COPD with PH. The obtaining of the index by Doppler tissue only requires recording of annular velocities and simple measurements of two time intervals. The index is 
also a sensitive method for estimating LV dysfunction. Repeated estimation of LV function using the MPI may offer useful information on patients with COPD. So we advise physician to assess LV and RV global function in COPD patients by using MPI and consider it as a routine noninvasive echocardiographic assessment and markers of LV and RV function in COPD patients with or without pulmonary hypertension.

This study demonstrated LV dysfunction as a result of COPD with PH. However, the clinical significance of the LV dysfunction is not clear. Further research is needed to investigate the prognostic significance of LV dysfunction because of COPD with PH. Finally, the impact of PH as a result of the other causes on LVMPI could also be investigated in the future.Further studies are needed to elucidate the specific mechanisms associated with COPD severity and left ventricular diastolic dysfunction.

\section{References}

[1]. World Health Report, World Health Organization, Geneva. Available from URL: http://www.who.int/whr/2000/en/ statistica.htm. 2000.

[2]. A.D. Lopez, K. Shibuya, C. Rao, et al. Chronic obstructive pulmonary disease: current burden and future projections. Eur. Respir. J.2006; 27 (2): 397-412.

[3]. J.A. Barbera, I. Blanco. Pulmonary hypertension in patients with chronic obstructive pulmonary disease: advances in pathophysiology and management. Drugs.2009; 69 (9): 1153-1171.

[4]. W. MacNee.Pathophysiology of corpulmonale in chronic obstructive pulmonary disease. Am. J. Respir. Crit. Care Med.1994; 150:833-852.

[5]. J.A. Barbera , V.I. Peinado, S. Santos. Pulmonary hypertension in chronic obstructive pulmonary disease. Eur. Respir. J.2003; 21:892-905.

[6]. K. Jorgensen, M.F. Muller, J. Nel, et al. Reduced intrathoracic blood volume and left and right ventricular dimensions in patients with severe emphysema: an MRI study. Chest .2007; 131:1050-1057.

[7]. Daniels LB, Krummen DE, Blanchard DG.Echocardiography in pulmonary vascular disease.CardiolClin. 2004; $22: 383-99$.

[8]. Macnee W. Pathophysiology of corpulmonale in chronic obstructive pulmonary disease.PartOne. Am J Respire Crit Care Med. 1994; 150:833-52.

[9]. Decramer M, Janssens W, Miravitlles M. "Chronic obstructive pulmonary disease". Lancet. 2012 ; April 379 (9823): 134151.Vestbo, Jørgen. "Definition and Overview". Global Strategy for the Diagnosis, Management, and Prevention of Chronic Obstructive Pulmonary Disease.Global Initiative for Chronic Obstructive Lung Disease. 2013; pp. 1-7.

[10]. Murphy DMF, Fishman AP. "Chapter 53". Fishman's Pulmonary Diseases and Disorders (4th ed.). McGraw-Hill.2008; p. 913.

[11]. Beasley, V.Joshi, PV. Singanayagam, et al. "Lung microbiology and exacerbations in COPD". International journal of chronic obstructive pulmonary disease.2012; 7: 555-69.

[12]. Calverley PM, Koulouris NG. "Flow limitation and dynamic hyperinflation: key concepts in modern respiratory physiology". EurRespir J. 2005; 25 (1): 186-199.

[13]. Currie, Graeme P. ABC of COPD (2nd ed.). Chichester, West Sussex, UK: Wiley-Blackwell, BMJ Books. 2010 ; p. 32.

[14]. O'Donnell DE."Hyperinflation, Dyspnea, and Exercise Intolerance in Chronic Obstructive Pulmonary Disease". The Proceedings of the American Thoracic Society. 2006;3 (2): 180-4.

[15]. Reilly, John J.; Silverman, Edwin K.; Shapiro, Steven D. "Chronic Obstructive Pulmonary Disease". In Longo, Dan; Fauci, Anthony; Kasper, Dennis; Hauser, Stephen; Jameson, J.; Loscalzo, Joseph. Harrison's Principles of Internal Medicine (18th ed.). McGraw Hill.2011; pp. 2151-9.

[16]. Rabe KF, Hurd S, Anzueto A, Barnes PJ, et al. "Global strategy for the diagnosis, management, and prevention of chronic obstructive pulmonary disease: GOLD executive summary". Am. J. Respir. Crit. Care Med. September $2007 ; 176$ (6): $532-55$.

[17]. Burrows B, Kettel LJ, Niden AH, et al. Patterns of cardiovascular dysfunction in chronic obstructive lung disease. N Engl J Med 1972; 286:912-918.

[18]. Hunninghake D. Cardiovascular disease in chronic obstructive pulmonary disease.Proc Am ThoracSoc 2005; 2:44-49.

[19]. Weitzenblum E, Hirth C, Ducolone A, Mirhom R, Rasaholinjanahary J, Ehrhart M. Prognostic value of pulmonary artery pressure in chronic obstructive pulmonary disease. Thorax 1981; 36:752-758.

[20]. Cooper R, Ghali J, Simmons BE, Castaner A. Elevated pulmonary artery pressure: an independent predictor of mortality. Chest 1991; 99:112-120.

[21]. Lung Health Study Research Group.Effect of inhaled triamcinolone on the decline in pulmonary function in chronic obstructive pulmonary disease. N Engl J Med 2000; 343:1902-1909.

[22]. Sidney S, Sorel M, Quesenberry CP, DeLuise C, Lanes S, Eisner MD. COPD and incident cardiovascular disease hospitalizations and mortality: Kaiser Permanente Medical Care Program. Chest.2005; 128: 2068-2075.

[23]. Weitzenblum E, Hirth C, Ducolone A, Mirhom R, Rasaholinjanahary J, Ehrhart M. Prognostic value of pulmonary artery pressure In chronic COPD. Thorax. 1981; 36:752-8.

[24]. Thabut G, Dauriat G, Stern JB, Logeart D, et al. Pulmonary haemodynamics in advanced COPD candidates for lung volume reduction surgery or lung transplantation. Chest. 2005; 127:1531-6.

[25]. Kessler R, Faller M, Weitzenblum E, Chaouat A, et al. "Natural history" of pulmonary hypertension in a series of 131 patients with chronic obstructive pulmonary disease. Am J RespirCrit Care Med. 2001; 164:219-24.

[26]. Weitzenblum E, Sautegeau A, Ehrhart M, et al. Long-term course of pulmonary arterial pressure in chronic obstructive pulmonary disease. Am Rev Respir Dis 1984; 130:993-998.

[27]. Weitzenblum E, Sautegeau A, Ehrhart M, etal.Long-term oxygen therapy can reverse the progression of pulmonary hypertension in patients with chronic obstructive pulmonary disease. Am Rev Respir Dis 1985; 131:493-498.

[28]. Kessler R, Faller M, Weitzenblum E, Chaouat A, Aykut A, Ducolone A, Ehrhart M, Oswald-Mammosser M. "Natural history" of pulmonary hypertension in a series of 131 patients with chronic obstructive pulmonary disease. Am J RespirCrit Care Med 2001; 164:219-224.

[29]. Leuchte HH, Baumgartner RA, Nounou ME, Vogeser M, Neurohr C, Trautnitz M, Behr J. Brain natriuretic peptide is a prognostic parameter in chronic lung disease. Am J RespirCrit Care Med. 2006; 173:744-750.

[30]. Oswald-Mammosser M, Weitzenblum E, Quoix E, Chaouat A, Charpentier C, Kessler R. Prognostic factors in COPD patients receiving long-term oxygen therapy: importance of pulmonary artery pressure. Chest.1995; 107:1193-1198.

[31]. Burgess MI, Mogulkoc N, Bright-Thomas RJ, et al. Comparison of echocardiographic markers of right ventricular function in determining prognosis in chronic pulmonary disease. Jam SocEchocardiogr. 2002; 15:633-639. 
[32]. Enson Y, Guintini C, Lewis ML, et al.The influence of hydrogen ion concentration and hypoxia on the pulmonary circulation. J Clin Invest. 1964; 43:1146-1162.

[33]. Durand J, Leroy-Ladurie M, Ransom-Bitker B. Effects of hypoxia and hypercapnia on the repartition of pulmonary blood flow in supine subjects. Respir Res. 1970; 5:156-165.

[34]. Wright JL, Petty T, Thurlbeck WM. Analysis of the structure of the muscular pulmonary arteries in patients with pulmonary hypertension and COPD: National Institutes of Health Nocturnal Oxygen Therapy Trial. Lung. 1992; 170:109-124.

[35]. Hale KA, Niewoehner DE, Cosio MG. Morphologic changes in the muscular pulmonary arteries: relationship to cigarette smoking, airway disease, and emphysema. Am Rev Respir Dis. 1980; 122:273-278.

[36]. Peinado V, Barbera J, Ramirez J, et al. Endothelial dysfunction in pulmonary arteries of patients with mild COPD. Am J Physiol Lung Cell Mol Physiol. 1998; 274:908-913.

[37]. Barbera JA, Riverola A, Roca J, et al. Pulmonary vascular abnormalities and ventilation-perfusion relationships in mild chronic obstructive pulmonary disease.Am J RespirCrit Care Med. 1994; 149:423-429.

[38]. Falk JA, Abdallah HY, Solomides CC, Criner GJ. Association of pulmonary artery wall hypertrophy with pulmonary hemodynamics in severe emphysema: a morphometric study. Am J RespirCrit Care Med. 2004; 169:A616.

[39]. Falk JA, Grookett TW, Abdallah HY, et al. Morphometric analysis of small pulmonary arteries in severe emphysema. Proc Am Thorac Soc. 2005; 2:140.

[40]. Dinh-Xuan A, Higenbottom T, Clelland C, Pepke-Zaba J, Cremona G, Butt AY, Large SR, Wells FC, Wallwork J. Impairment of endothelium-dependent pulmonary artery relaxation in chronic obstructive lung disease. N Engl J Med. 1991; 324:1539-1547.

[41]. Giaid A, Saleh D. Reduced expression of endothelial nitric oxide synthase in the lungs of patients with pulmonary hypertension. N Engl JMed.1995; 333:214-221.

[42]. Lee J, Tarasevicience-Stewart L, Keith R, Geraci M, Voelkel N. The expression of prostacyclin synthase is decreased in the small pulmonary arteries of patients with emphysema. Chest 2005; 128:575S.

[43]. Celik G, Karabiyikoglu G. Local and peripheral plasma endothelin-1 in pulmonary hypertension secondary to chronic obstructive pulmonary disease.Respiration.1998; 65:289-294.

[44]. Voelkel N, Cool C. Pulmonary vascular involvement in chronic obstructive pulmonary disease.EurRespir J. 2003; 46:28-32.

[45]. Santos S, Peinado VI, Ramirez J, Morales-Blanhir J, Bastos R, Roca J, Rodriguez-Roisin R, BarberaJA.Enhanced expression of vascular endothelial growth factor in pulmonary arteries of smokers and patients with moderate chronic obstructive pulmonary disease.Am J RespirCrit Care Med. 2003; 167:1250-1256.

[46]. Eddahibi S, Chaouat A, Morrell N, Fadel E, et al. Polymorphism of the serotonin transporter gene and pulmonary hypertension in chronic obstructive pulmonary disease. Circulation.2003; 108:1839-1844.

[47]. Peinado V, Barbera J, Abate P, et al. Inflammatory reaction in pulmonary muscular arteries of patients with chronic obstructive pulmonary disease. Am J RespirCrit Care Med. 1999; 159:1605-1611.

[48]. Saetta M, Baraldo S, Corbino L, et al. CD8 cells in the lungs of smokers with chronic obstructive pulmonary diesase. Am J RespirCrit Care Med. 1999; 160:711-717.

[49]. Sciurba FC, Rogers RM, Keenan RJ, Slivka WA, Gorcsan J, Ferson PF, Holbert JM, Brown ML, Landreneau RJ. Improvement in pulmonary function and elastic recoil after lung-reduction surgery for diffuse emphysema.NEngl J Med. 1996; 334:1095-1099.

[50]. Falk JA, Martin UJ, Scharf SM, Criner GJ. Lung elastic recoil does not correlate with pulmonary hemodynamics in severe emphysema. Chest .2007; 132:1476-1484.

[51]. Criner GJ, Scharf SM, Falk JA, Gaughan JP, Sternberg AL, Patel NB, Fessler HE, Minai OA, Fishman AP. Effect of lung volume reduction surgery on resting pulmonary hemodynamics in severe emphysema. Am J RespirCrit Care Med. 2007; 176:253-260.

[52]. Wright JL, Lawson L, Pare PD, et al. The structure and function of the pulmonary vasculature in mild chronic obstructive pulmonary disease: the effect of oxygen and exercise. Am Rev Respir Dis.1983; 128:702-707.

[53]. Currie PJ, Seward JB, Chan K-L, et al. Continuous wave Doppler estimation of right ventricular pressure: a simultaneous Dopplercatheterization study in 127 patients. J Am Coll Cardiol.1985; 6:750-756.

[54]. Arcasoy SM, Christie JD, Ferrari VA, et al. Echocardiographic assessment of pulmonary hypertension in patients with advanced lung disease. Am J RespirCrit Care Med. 2003; 167:735-740.

[55]. Richards AM, Nicholls MG, Espiner EA, et al. B-type natriuretic peptides and ejection fraction for prognosis after myocardial infarction. Circulation.2003; 107:2786.

[56]. Kruger S, Graf J, Kunz D, et al. Brain natriuretic peptide levels predict functional capacity in patients with chronic heart failure. $\mathrm{J}$ Am CollCardiol. 2002; 40:718-722.

[57]. Sin DD, Man SF. Why are patients with chronic obstructive pulmonary disease at increased risk of cardiovascular diseases? The potential role of systemic inflammation in chronic obstructive pulmonary disease.Circulation.2003; 107:1514-1519.

[58]. Danesh J, Whincup P, Walker M, Lennon L, Thomson A, Appleby P, Gallimore JR, Pepys MB. Low-grade inflammation and coronary heart disease: prospective study and updated meta-analyses. BMJ.2000; 321:199-204.

[59]. Black S, Kushner I, Samols D. C-reactive protein. J BiolChem 2004; 279:48487-48490.

[60]. Pinto-Plata VM, Mullerova H, Toso JF, Feudjo-Tepie M, Soriano JB, Vessey RS, Celli BR. C-reactive protein in patients with COPD, control smokers and non-smokers. Thorax 2006; 61:23-28.

[61]. Broekhuizen R, Wouters EF, Creutzberg EC, ScholsAM. Raised CRP levels mark metabolic and functional impairment in advanced COPD. Thorax 2006; 61:17-22.

[62]. Dahl M, Vestbo J, Lange P, Bojesen SE, Tybjaerg-Hansen A, Nordestgaard BG. C-reactive protein as a predictor of prognosis in chronic obstructive pulmonary disease. Am J RespirCrit Care Med 2007; 175:250-255.

[63]. Pearson TA, Mensah GA, Alexander RW, et al. Centers for Disease Control and Prevention; American Heart Association. Markers of inflammation and cardiovascular disease: application to clinical and public health practice: a statement for healthcare professionals from the Centers for Disease Control and Prevention and the American Heart Association. Circulation 2003; 107:499511.

[64]. Ridker PM; JUPITER Study Group.Rosuvastatin in the primary prevention of cardiovascular disease among patients with low levels of low-density lipoprotein cholesterol and elevated high-sensitivity C-reactive protein: rationale and design of the JUPITER trial. Circulation 2003; 108:2292-2297.

[65]. Albert MA, Danielson E, Rifai N, et al. Effect of statin therapy on C-reactive protein levels: the Pravastatin Inflammation/CRP Evaluation (PRINCE): a randomized trial and cohort study. JAMA 2001; 286: 64-70.

[66]. Soyseth V, Brekke P, Smith P, Omland T. Statin use is associated with reduced mortality in COPD. EurRespir J 2007; 2:279-283

[67]. Balan KK, Critchley M. Is the dyspnea during adenosine cardiac stress test caused by bronchospasm? Am Heart J 2001; 142:142145. 
[68]. Thurnheer R, Laube I, Kaufmann PA, et al. Practicability and safety of dipyridamole cardiac imaging in patients with severe chronic obstructive pulmonary disease.Eur J Nucl Med 1999; 26:812-817.

[69]. Mathias W, Arruda A, Santos FC, Arruda AL, Mattos E, Osorio A, Campos O, Gil M, Andrade JL, Carvalho AC. Safety of dobutamineatropine stress echocardiography: a prospective experience of 4,033 consecutive studies. J Am SocEchocardiogr. 1999; 12:785-791.

[70]. Geleijnse ML, Fioretti PM, Roelandt JR. Methodology, feasibility, safety and diagnostic accuracy of dobutamine stress echocardiography. J Am CollCardiol. 1997; 30:595-606.

[71]. Nikolaou K, Knez A, Rist C, et al. Accuracy of 64-MDCT in the diagnosis of ischemic heart disease. AJR Am J Roentgenol 2006; 187:111-117.

[72]. Buch P, Friberg J, Scharling H, Lange P, Prescott E. Reduced lung function and the risk of atrial fibrillation in the Copenhagen City Heart Study. EurRespir J 2003; 21:1012-1016.

[73]. McCord J, Borzak S. Multifocal atrial tachycardia.Chest 1998; 113:203-209.

[74]. Mivris DM, Goldberger AL. Electrocardiography. In: Libby P, Bonow RO, Mann DL, Zipes DP, eds. Braunwald's Heart Disease. A text book of cardiovascular medicine. Philadelphia, PA, USA: Saunders Elsevier. 2008; 149-93.

[75]. Kothari SA, Apiyasawat S, Asad N, SpodickDH.Evidence supporting a new rate threshold for multifocal atrial tachycardia.ClinCardiol 2005; 28:561-563.

[76]. Standardization of spirometry-1987 update.Statement of the American Thoracic Society.Am Rev Respir Dis 1987; 136: 1285-98.

[77]. Fabbri LM, Luppi F, Beghe B, Rabe KF. Update in chronic obstructive pulmonary disease 2005. Am J RespirCrit Care Med. 2006; 173(10):105665.

[78]. Global strategy for the diagnosis, management, and prevention of chronic obstructive pulmonary disease, Global initiative for chronic obstructive pulmonary disease (GOLD), 2010. Availablefrom: http://www.goldcopd.org.

[79]. Teichholz LE, Kreulen T, Herman MV, Gorlin R. Problems in echocardiographic volume determinations: echocardiographicangiographic correlations in the presence of absence of asynergy. Am J Cardiol.1976; 37:7-11.

[80]. Sahn DJ, DeMaria A, Kisslo J, Weyman A. The committee on M-mode standardization of the American Society of Echocardiography: recommendations regarding quantitation in $\mathrm{M}$ mode echocardiography; results of a survey of echocardiographic measurements. Circulation 1978; 58:1072-83

[81]. Kaul S, Tei C, Hopkins JM, Shah PM. Assessment of right ventricular function using two-dimensional echocardiography.Am Heart J 1984; 107:526-31.

[82]. Tei C, Ling LH, Hodge DO, Bailey KR, Oh JK, Rodeheffer RJ, et al. New index of combined systolic and diastolic myocardial performance: a simple and reproducible measure of cardiac function-a study in normals and dilated cardiomyopathy. J Cardiol $1995 ; 26: 357-66$

[83]. Tei C, Nishimura RA, Seward JB, Tajik AJ. Noninvasive Doppler-derived myocardial performance index: correlation with simultaneous measurements of cardiac catheterization measurements. J Am SocEchocardiogr 1997; 10:169-78.

[84]. Braunwald's Heart Disease. 8th Edition. By Libby P, Bonow RO, ZipesDP, Mann DL. Philadelphia: Saunders 2008. p. 251.

[85]. Kaul S, Tei C, Hopkins JM, Shah PM. Assessment of right ventricular function using two-dimensional echocardiography.Am Heart J 1984;107:526-31

[86]. Appleton CP, Jensen JL, Hatle LK, Oh JK. Doppler evaluation of left and right ventricular diastolic function: a technical guide for obtaining optimal flow velocity recordings. J AmSocEchocardiogr.1997; 10:271-92.

[87]. Rudski LG, Lai WW, Afilalo J, Hua L, Handschumacher MD, Chandrasekaran K, et al. Guidelines for the echocardiographic assessment of the right heart in adults: a report from the American Society of Echocardiography endorsed by the European Association of Echocardiography, a registered branch of the European Society of Cardiology, and the Canadian Society of Echocardiography. J Am SocEchocardiogr 2010; 23(7):685-713.

[88]. Badesch DB, Champion HC, Sanchez MA, et al. Diagnosis and assessment of pulmonary arterial hypertension. J Am CollCardiol 2009; 54: 55-66.

[89]. Graettinger WF, Greene ER, VoylesWF.Doppler predictions of pulmonary artery pressure, flow, and resistance in adults. Am Heart J. 1987; 113(6):1426-1437.

[90]. Serra W, Chetta A, Santilli D, Mozzani F, Dall'Aglio PP, Olivieri D, et al. Echocardiography may help detect pulmonary vasculopathy in the early stages of pulmonary artery hypertension associated with systemic sclerosis. Cardiovasc Ultrasound. 2010; $8: 25$.

[91]. Grifoni S, Olivotto I, Cecchini P, et al. Short-term clinical outcome of patients with acute pulmonary embolism, normal blood pressure, and echocardiographic right ventricular dysfunction. Circulation. 2000; 101(24):2817-2822.

[92]. N.B. Schiller, P.M. Shah, M. Crawford, et al,Recommendations for quantitation of the left ventricle by two-dimensional echocardiography. American Society of Echocardiography Committee on Standards, Subcommittee onQuantitation of TwoDimensional Echocardiograms, J. Am.Soc. Echocardiogr. 1989;2:358-367.

[93]. C. Tei, R.A. Nishimura, J.B. Seward, et al, Noninvasive Doppler derived myocardial performance index: correlation with simultaneous measurements of cardiac catheterization measurements, J. Am. Soc. Echocardiogr. 1997; 10:169-178.

[94]. Badesch DB, Champion HC, Sanchez MA, Hoeper MM, Loyd JE, Manes A, et al. Diagnosis and assessment of pulmonary arterial hypertension. J Am CollCardiol. 2009; 54: 55-66.

[95]. Alpert SA. The effect of right ventricular dysfunction on left ventricular form and function. Chest.2001; 119: 1632-1633.

[96]. Louie EK, Rich S, Brundage BH. Doppler echocardiographic assessment of impaired left ventricular filling in patients with right ventricular pressure overload due to primary pulmonary hypertension. J Am CollCardiol. 1986; 6: 1298-1306.

[97]. S. Aggarwa, A. Meena, N. Kaur, R. Bachhal, R.S. Sidhu, Autonomic nervous system changes in chronic obstructive pulmonary disease (COPD) patients, J. Clin. Diagn. Res. 2011; 5 (8):1533-1536.

[98]. S.K. Chhabra, S. De.Cardiovascular autonomic neuropathy in chronic obstructive pulmonary disease.Respir. Med. 2005; 99 (1):126-133.

[99]. Poulsen SH, Nielsen JC, Andersen HR.The influence of heart rate on the Doppler-derived myocardial performance index. J Am SocEchocardiogr 2000; 13:379-84.

[100]. Tei C, Ling LH, Hodge DO, Bailey KR, Oh JK, Rodeheffer RJ, et al. New index of combined systolic and diastolic myocardial performance: a simple and reproducible measure of cardiac function-a study in normal and dilated cardiomyopathy. J Cardiol.1995; 26:357-66.

[101]. Tei C, Nishimura RA, Seward JB, Tajik AJ. Noninvasive Doppler-derived myocardial performance index: correlation with simultaneous measurements of cardiac catheterization measurements. J Am SocEchocardiogr 1997; 10:169-78.

[102]. Tei C, Dujardin KS, Hodge DO, Kyle RA, Tajik AJ, Seward JB. Doppler index combining systolic and diastolic myocardial performance: clinical value in cardiac amyloidosis. J Am CollCardiol. 1996; 28:658-64. 
[103]. Weissler AM, Harris WS, Schoenfeld CD. Systolic time intervals in heart failure in man.Circulation 1968; 37:149-59.

[104]. E. Suchon', W. Tracz, P. Podolec, et al, Evaluation of left ventricular function in patients with chronic obstructive pulmonary disease, Pol. Arch. Med. Wewn. 2007; 117 (3): 86-90.

[105]. Schena M, Clini E, Errera D, et al. Echo-Doppler evaluation of left ventricular impairment in chronic corpulmonale. Chest.1996; 109: 1446-1451.

[106]. Vonk-Noordergraaf A, Marcus T, Holverda S, et al.Early changes of cardiac structure and function in COPD patients with mild hypoxemia.Chest.2005; 127: 1898-1902.

[107]. Matthay R, Berger H, Davis R, et al. Right and left ventricular exercise performance in chronic obstructive pulmonary disease: Radionuclide assessment. Ann Int Med. 1980; 93: 234-239.

[108]. Yilmaz R, Gencer M, Ceylan E, et al. Impact of chronic obstructive pulmonary disease with pulmonary hypertension on both left ventricular systolic and diastolic performance. J Am SocEchocardiogr. 2005; 18: 873-881.

[109]. Vizza CD, Lynch JP, Ochoa LL, et al.Right and left ventricular impairment in patients with severe pulmonary disease.Chest.1998; 113: 576-583

[110]. A. Moustapha, V. Kaushik, S. Diaz, et al, Echocardiographic evaluation of left-ventricular diastolic function in patients with chronic pulmonary hypertension, Cardiology.2001; 95: 96-100.

[111]. E. Barasch, A. Moustapha, V. Kaushik, S. Diaz, S.H. Kang, Quantitative relationship between severity of pulmonary hypertension and LV diastolic function has been established FREE, J. Am. Coll. Cardiol. 2003; 41 (6): 1066

[112]. N.K. Gupta, R.K. Agrawal, A.B. Srivastav, M.L. Ved, Echocardiographic evaluation of heart in chronic obstructivepulmonary disease patient and its co-relation with the severity of disease, Lung India. 2011; 28 (2): 105-109.

[113]. Bristow JD, Morris JF, KlosterFE.Hemodynamics of corpulmonale.ProgCardiovasc Dis. 1966; 9:239-58

[114]. Kaul S, Tei C, Hopkins JM, Shah PM. Assessment of right ventricular function using two-dimensional echocardiography.Am Heart J 1984; 107:526-31.

[115]. Izzo A, Galderisi M, de DivitiisO.The influence of left systolic ventricular function on right ventricular function after an acute myocardial infarct.Cardiology 1998; 43:173-80.

[116]. De Groote P, Millaire A, Foucher-Hossein C, et al. Right ventricular ejection fraction is an independent predictor of survival in patients with moderate heart failure. J Am CollCardiol. 1998; 32: 948-54.

[117]. B. Lamia, L.C. Molano, D. Mouton, J.F. Muir, A. Cuvelier, Echocardiographic diagnosis of left ventricular diastolic dysfunction in COPD patients with pulmonary arterial hypertension, Am. J. Respir. Crit. Care Med. 2009; 179: 1484.

[118]. Boussuges A, Pinet C, Molenat F, et al. Left atrial and ventricular filling in chronic obstructive pulmonary disease. An echocardiographic and Doppler study.Am J RespirCrit Care Med. 2000; 162: 670-675.

[119]. Ozer N, Tokgozulu L, Coplu L, et al. Echocardiographic evaluation of left and right ventricular diastolic function in patients with chronic obstructive pulmonary disease. J Am SocEchocardiogr. 2001; 14: 557-561.

[120]. Tutar E, Kaya A, Gulec S, et al. Echocardiographic evaluation of left ventricular diastolic function in chronic corpulmonale. Am J Cardiol.1999; 83: 1414-1417.

[121]. Moustapha A, Kaushik V, Diaz S, et al. Echocardiographic evaluation of left-ventricular diastolic function in patients with chronic pulmonary hypertension. Cardiology.2001; 95: 96-100.

[122]. G.C. Funk, I. Lang, P. Schenk, et al, Left ventricular diastolic dysfunction in patients with COPD in the presence and absence of elevated pulmonary arterial pressure, Chest 133 (2008) 1354-1359.

[123]. E. Barasch, A. Moustapha, V. Kaushik, S. Diaz, S.H. Kang, Quantitative relationship between severity of pulmonary hypertension and LV diastolic function has been established FREE, J. Am. Coll. Cardiol. 2003; 41 (6): 1066.

[124]. K.L. Davis, U. Mehlhorn, G.A. Laine, S.J. Allen, Myocardial edema, left ventricular function and pulmonary hypertension, J. Appl. Physiol. 1995; 78: 132-137.

[125]. V. Bhargava, K.S. Sunnerhagen, Left ventricular asynchrony in patients with pulmonary hypertension, J. Appl. Physiol. 1990; 69 (2): 517-522.

[126]. H.C. Dittrich, L.C. Chow, P.H. Nicod, Early improvement in left ventricular diastolic function after relief of chronic right ventricular pressure overload, Circulation. 1989; 80 (4): 823-830.

[127]. M. Kasner, D. Westermann, D. Steendijk, et al, LV Dysfunction Induced by a non-severe idiopathic pulmonary arterial hypertension. A pressure-volume relationship study, Am. J. Respir. Crit. Care Med. 2012; 186 (2) :181-189.

[128]. V. Bhargava, K.S. Sunnerhagen, Left ventricular asynchrony in patients with pulmonary hypertension, J. Appl. Physiol. 1990; 69 (2):517-522

[129]. C.T.J. Gan, J.W. Lankhaar, J.T. Marcus, et al, Impaired left ventricular filling due to right-to-left ventricular interaction in patients with pulmonary arterial hypertension, Am. J. Physiol. Heart Circ. Physiol. 2006; 290:1528-1533.

[130]. Marangoni S, Scalvini S, Schena M, Vitacca M, Quadri A, Levi G. Right ventricular diastolic function in chronic obstructive lung disease.EurRespir J. 1992;5:438-43.

[131]. Ozer N, Tokgozoglu L, Coplu L, Kes S. Echocardiographic evaluation of left and right ventricular diastolic function in patients with chronic obstructive pulmonary disease. J AmSocEchocardiogr 2001; 14:557-61.

[132]. Caso P, Galderisi M, Cicala S, Cioppa C, D'Andrea A, Lagioia G, et al. Association between myocardial right ventricular relaxation time and pulmonary arterial pressure in chronic obstructive lung disease: analysis by pulsed Doppler tissue imaging. J Am SocEchocardiogr. 2001; 14:970-7.

[133]. Medical Research Council Definition and classification of chronic bionchitis for clinical and epidemiological purposes Crofton and Douglass Respiratory Diseases 4th Ed 1965 p 490.

[134]. A. Vonk-Noordergraaf, T. Marcus, S. Holverda, et al, Early changes of cardiac structure and function in COPD patients with mild hypoxemia. Chest.2005; 127:1898-1902.

[135]. Tei C, Ling LH, Hodge DO, Bailey KR, Oh JK, Rodeheffer RJ, et al. New index of combined systolic and diastolic myocardial performance: a simple and reproducible measure of cardiac function-a study in normals and dilated cardiomyopathy. J Cardiol.1995; 26:357-66.

[136]. Tei C, Dujardin KS, Hodge DO, Bailey KR, McGoon MD, Tajik AJ, et al. Doppler echocardiographic index for assessment of global right ventricular function. J Am SocEchocardiogr. 1996; 9:838-47.

[137]. Dujardin KS, Tei C, Yeo TC, Hodge DO, Rossi A, Seward JB. Prognostic value of a Doppler index combining systolic and diastolic performance in idiopathic-dilated cardiomyopathy.Am J Cardiol.1998; 82:1071-6.

[138]. Tei C, Nishimura RA, Seward JB, Tajik AJ. Noninvasive Doppler-derived myocardial performance index: correlation with simultaneous measurements of cardiac catheterization measurements. J Am SocEchocardiogr 1997; 10:169-78.

[139]. Tei C, Dujardin KS, Hodge DO, Kyle RA, Tajik AJ, Seward JB. Doppler index combining systolic and diastolic myocardial performance: clinical value in cardiac amyloidosis. J Am CollCardiol. 1996; 28:658-64. 
[140]. Eidem BW, Tei C, O’Leary PW, Cetta F, Seward JB.Nongeometric quantitative assessment of right and left ventricular function: myocardial performance index in normal children and patients with Ebstein anomaly. J Am SocEchocardiogr. 1998; 11:849-56.

[141]. Poulsen SH, Jensen SE, Nielsen JC, Moller JE, Egstrup K. Serial changes and prognostic implications of a Dopplerderived index of combined left ventricular systolic and diastolic myocardial performance in acute myocardial infarction. Am J Cardiol.2000; 85:1925 .

[142]. Harada K, Tamura M, Toyono M, Oyama K, Takada G. Assessment of global left ventricular function by tissue Doppler imaging. Am J Cardiol 2001; 88:927-32.

[143]. Tekten T, Onbasili AO, Ceyhan C, Unal S, Discigil B. Novel approach to measure myocardial performance index: pulsed wave tissue Doppler echocardiography. Echocardiography 2003; 20:503-10.

[144]. R. Orr, L.J. Smith, M.J. Cuttica, Pulmonary hypertension in advanced chronic obstructive pulmonary disease, Curr. Opin.Pulm. Med. 2012; 18 (2):138-143.

[145]. E. Weitzenblum, A. Sautegeau, M. Ehrhart, et al, Long term course of pulmonary artery pressure in COPD, Am. Rev. Respir. Dis. 1984; 130: 993-998.

[146]. G. Thabut, G. Dauriat, J.B. Stern, et al, Pulmonary haemodynamics in advanced COPD candidates for lung volume reduction surgery or lung transplantation, Chest. 2005; 127: 1531-1536.

[147]. Chaouat A, Bugnet AS, Kadaoui N. Severe pulmonary hypertension and chronic obstructive pulmonary disease.Am J RespirCrit Care Med. 2005; 172: 189-194.

[148]. Weitzenblum E, ChaouatA.Right ventricular function in COPD. Can it be assessed reliably by the measurements of right ventricular ejection fraction? Chest. 1998;113: 567-568.

[149]. N.K. Gupta, R.K. Agrawal, A.B. Srivastav, M.L. Ved, Echocardiographic evaluation of heart in chronic obstructive pulmonary disease patient and its co-relation with the severity of disease, Lung India. 2011; 28 (2): 105-109.

[150]. R.G. Barr, D.A. Bluemke, F.S. Ahmed, et al, Percent emphysema, airflow obstruction, and impaired left ventricular filling, N. Engl. J. Med. 362. 2010; (3): 217-227.

[151]. B.A. Marzluf, B. Burian, K. Vonbank, et al, Relevance of pulmonary hypertension in COPD prevalence of resting and exercise induced pulmonary hypertension at different stages of COPD. Eur. Respir. J. 2007; 30: 608.

[152]. J.A. Barbera`, A. Riverola, J. Roca, et al, Pulmonary vascular abnormalities and ventilation-perfusion relationships in mild chronic obstructive pulmonary disease, Am. J. Respir. Crit. Care Med. 1994; 149: 423-429.

[153]. V.I. Peinado, J.A. Barbera, J. Ramirez, et al, Endothelial dysfunction in pulmonary arteries of patients with mild COPD, Am. J. Physiol. 1998; 274 :908-913.

[154]. S. Santos, V.I. Peinado, J. Ramirez, et al, Characterization of pulmonary vascular remodelling in smokers and patients with mild COPD. Eur. Respir. J. 2002; 19: 632-638.

[155]. J.A. Barbera', I. Blanco, Pulmonary hypertension in patients with chronic obstructive pulmonary disease: advances in pathophysiology and management, Drugs 69. 2009; (9):1153-1171.

[156]. Hatle L, Angelsen BAJ, Tromsdaal A. Noninvasive estimation of pulmonary artery systolic pressure with Doppler ultrasound. Br Heart J. 1981; 45:157-6 